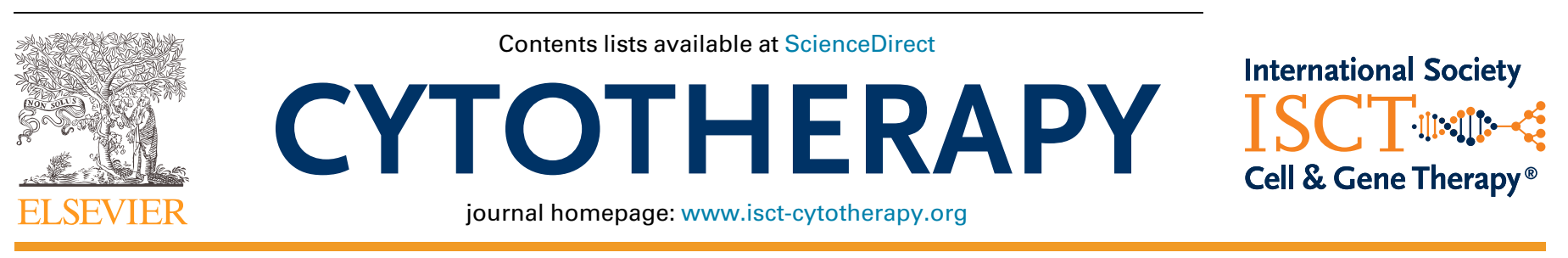

Review

\title{
Stem cell therapy in coronavirus disease 2019: current evidence and future potential
}

\author{
Rohit Shetty ${ }^{1}$, Ponnalagu Murugeswari ${ }^{2}$, Koushik Chakrabarty ${ }^{3}$, Chaitra Jayadev ${ }^{4}$, \\ Himanshu Matalia ${ }^{1}$, Arkasubhra Ghosh ${ }^{3}$, Debashish Das ${ }^{2, *}$ \\ ${ }^{1}$ Department of Cornea and Refractive Surgery, Narayana Nethralaya Eye Institute, Bangalore, India \\ ${ }^{2}$ Stem Cell Research Laboratory, GROW Laboratory, Narayana Nethralaya Foundation, Bangalore, India \\ ${ }^{3}$ GROW Laboratory, Narayana Nethralaya Foundation, Bangalore, India \\ ${ }^{4}$ Department of Vitreo-Retinal Surgery, Narayana Nethralaya Eye Institute, Bangalore, India
}

\section{A R T I C L E I N F O}

\section{Article History:}

Received 26 August 2020

Accepted 2 November 2020

\begin{abstract}
A B S T R A C T
The end of 2019 saw the beginning of the coronavirus disease 2019 (COVID-19) pandemic that soared in 2020, affecting 215 countries worldwide, with no signs of abating. In an effort to contain the spread of the disease and treat the infected, researchers are racing against several odds to find an effective solution. The unavailability of timely and affordable or definitive treatment has caused significant morbidity and mortality. Acute respiratory distress syndrome (ARDS) caused by an unregulated host inflammatory response toward the viral infection, followed by multi-organ dysfunction or failure, is one of the primary causes of death in severe cases of COVID-19 infection. Currently, empirical management of respiratory and hematological manifestations along with anti-viral agents is being used to treat the infection. The quest is on for both a vaccine and a more definitive management protocol to curtail the spread. Researchers and clinicians are also exploring the possibility of using cell therapy for severe cases of COVID-19 with ARDS. Mesenchymal stromal cells are known to have immunomodulatory properties and have previously been used to treat viral infections. This review explores the potential of mesenchymal stromal cells as cell therapy for ARDS.
\end{abstract}

(c) 2020 International Society for Cell \& Gene Therapy. Published by Elsevier Inc. All rights reserved.

\section{Introduction}

The latter half of 2019 saw a sudden rise in pneumonia or severe respiratory infection in Wuhan, Hubei Province, China, secondary to a novel coronavirus-severe acute respiratory syndrome coronavirus 2 (SARS-CoV-2) [1]. The infectivity of SARS-COV-2 surpassed the pace of finding an effective treatment or preventive option, and as of October 27,2020 , there are $43,341,451$ confirmed positive cases, with a mortality rate of $2.6 \%$ and a recovery rate of $73 \%$ (www.WHO.int).

A pathogen's basic reproduction number (R0) denotes the average number of people who can be infected by an infected individual. Though the R0 of coronavirus disease 2019 (COVID-19) differs between countries, it is higher than 1 , suggesting an exponential infectivity potential of the virus, which has led to this pandemic [2,3]. The R0 of COVID-19 (2-3) and that of Spanish influenza is similar but higher than that of H1N1 influenza (1.46-1.52) and Middle East respiratory syndrome $(0.3-0.8)[4-6]$.

\footnotetext{
* Correspondence: Debashish Das, Stem Cell Research Laboratory, GROW Laboratory, Narayana Nethralaya Foundation, Narayana Nethralaya Eye Institute, Narayana Health City, Bommasandra, Bangalore-560 099, Karnataka, India.

E-mail addresses: dasdebashish@yahoo.co.uk, drdebashish@narayananethralaya. com (D. Das).
}

Although a majority of patients with COVID-19 infection are asymptomatic, symptoms can range from mild to severe [7-9]. Pneumonia, respiratory distress, multi-organ dysfunction, sepsis, septic shock, loss of speech and movement are signs of severity [10]. The elderly and immune-compromised and those with comorbidities have a higher risk of developing severe symptoms with a fatal outcome $[11,12]$. The virus-induced cytokine storm results in COVIDspecific acute respiratory distress syndrome (ARDS), multi-organ dysfunction syndrome and eventual death [13].

Currently, severely affected patients are being treated with antiviral and anti-inflammatory drugs, besides supportive measures such as invasive and non-invasive mechanical ventilation [14]. Acute progressive renal injury, an early marker of multi-organ dysfunction syndrome, requires renal replacement therapy in advanced disease [15]. Horby et al. [16] found that dexamethasone reduced mortality in patients receiving invasive ventilation but not in those without any respiratory support. Although treatment with several anti-virals did not lead to any improvement $[17,18]$, patients receiving remdesivir, an RNA polymerase inhibitor, demonstrated significant clinical improvement [19]. Over 50 clinical trials have been registered at ClinicalTrials.gov for investigating the safety and efficacy of the anti-viral favipiravir for COVID-19 treatment. 
The usage of chloroquine and hydroxychloroquine for COVID-19 treatment remains inconclusive [20,21]. Anakinra, an IL-1 receptor antagonist, has shown beneficial effects in moderate to severe COVID-19 infections [22,23]. Tocilizumab and sarilumab, both IL-6 receptor antagonists, used in small cohorts, have alleviated clinical symptoms without oxygen supplementation [24]. Ongoing trials will clear ambiguity on tocilizumab dosage and mortality post-treatment. Janus kinase signal inducer pathway inhibitors ruxolitinib and baricitinib are also being investigated [25,26]. Convalescent plasma therapy also has potential, but safety and efficacy have to be established with larger studies [27-29].

With an increasing number of infections worldwide, there is a pressing need to find a method of prevention and treatment for COVID-19. Vaccines are being developed, with one from Oxford University in collaboration with AstraZeneca in a phase 3 trial [30,31]. Although 300 clinical trials for investigating anti-viral drugs and 163 for anti-inflammatory drugs are ongoing, it is imperative to look for newer and alternate modalities to treat COVID-19 patients. Researchers have explored the role of stem cells in suppressing ARDS during the cytokine storm since mesenchymal stromal cells are known to play an immunomodulatory role $[1,32]$.

SARS-CoV-2 belongs to the Coronaviridae family, has a $5 \%$ genetic association with the SARS virus [33] and was given the nomenclature of COVID-19 by the Director General of the World Health Organization on January 30, 2020 [34]. The spike protein on the virus recognizes the spike protein present on angiotensin-converting enzyme 2 (ACE-2), making it the port of entry into the host cells [35]. The ACE-2 receptor is present ubiquitously and predominantly in the alveolar cells, making the lungs the most vulnerable to infection [36]. ACE-2 receptors have not been detected in bone marrow, lymph nodes, thymus, spleen, lymphocytes or macrophages [37]. Transmembrane protease serine 2 also plays a decisive role in viral entry into the host cells [38].

The overdrive that occurs in the host immune system in response to the virus also adversely affects the host cells [39]. Pro-inflammatory cytokines such as IL-7, IL-6, Il-2, tumor necrosis factor (TNF), MIP1A, interferon gamma-induced protein 10 and granulocyte colony-stimulating factor and chemokines such as CCL2, CCL3, CCL5, CXCL8, CXCL9 and CXCL10 are released during the infection [40,41]. The inflammatory response of the host can cause dysfunctional air exchange, pulmonary edema, cardiac injury and ARDS, eventually leading to death. Such an effect is called a cytokine storm and is reported in graft-versus-host disease during graft failure as well as in advanced stages of COVID-19 infection [42]. It has been reported to occur with a short median time of 8 days from the appearance of the first symptom to ARDS [43]. Hence, trials of multiple treatment modalities and strategies are being used, including anti-viral therapy, hydroxychloroquine, neutralizing antibodies, convalescent plasma therapy, repurposed anti-viral medications and blockers of ACE-2 receptor with antibodies $[44,45]$.

\section{Mesenchymal stromal cells as a potential therapeutic strategy}

Mesenchymal stromal cells (MSCs) are multi-potent adult stem cells with immunomodulatory properties [46]. They are found in bone marrow, adipose tissue, dental pulp, umbilical cord, placenta, Wharton's jelly, amniotic fluid, skin, foreskin, salivary gland and cord blood (Figure 1) [47]. The versatility of the differentiation potential of MSCs is based on the tissue-specific source of the cells [46]. According to the International Society for Cell \& Gene Therapy, MSCs are characterized by their ability to adhere to plastic surfaces as well as their expression

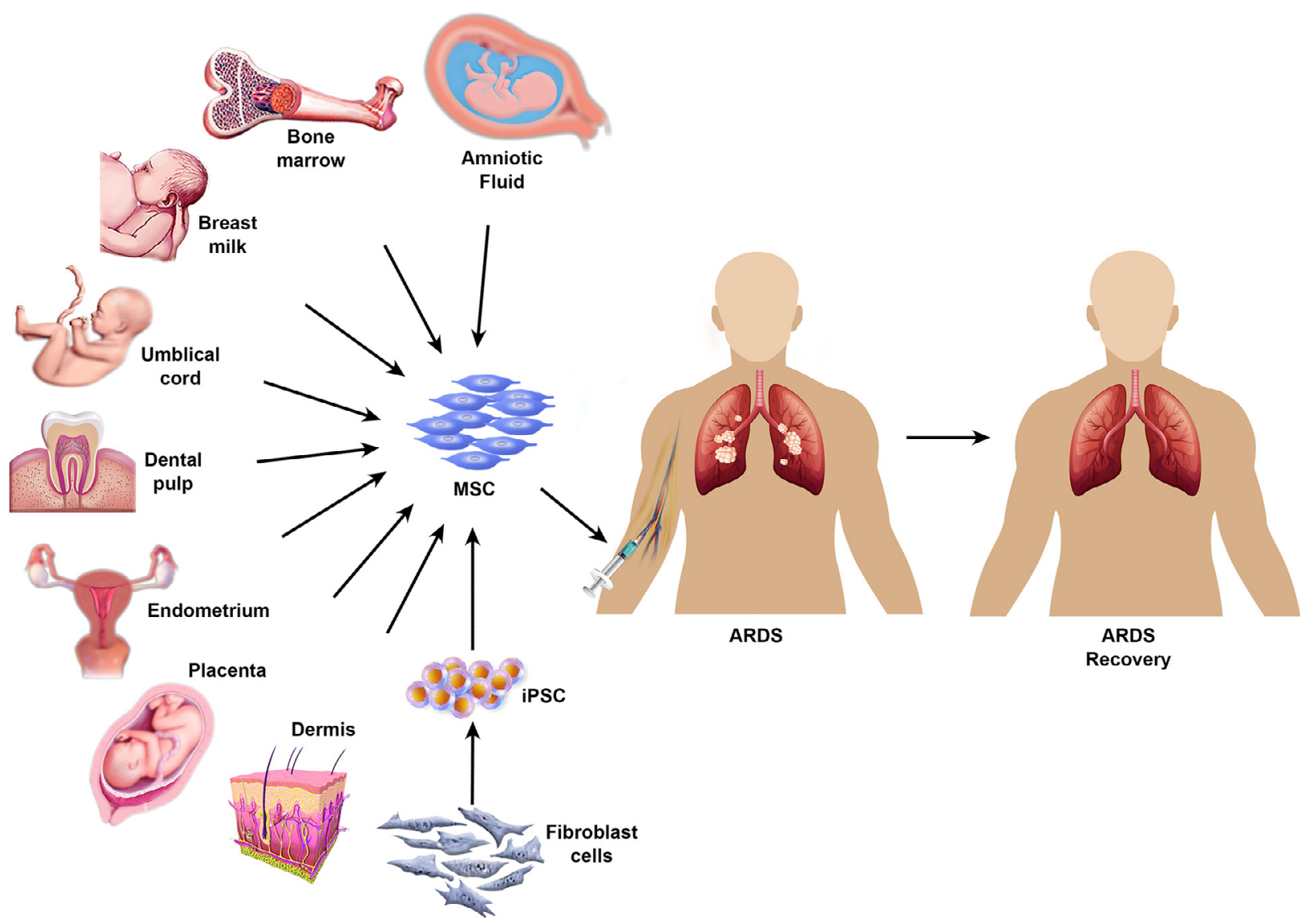

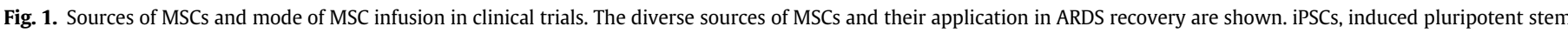
cells. (Color version of figure is available online). 
of CD105, CD73 and CD90 and lack of CD45, CD34, CD14, CD11b, CD79, CD 19 and HLA-DR $[48,49]$. The multi-potency of MSCs is validated by their ability to differentiate into adipocytes, chondroblasts and osteoblasts [49]. They have been widely used to aid in the regeneration of damaged neurons or muscle fibers and to suppress immune reactions via anti-inflammatory macrophages and regulatory T cells [50]. MSCs express low levels of major histocompatibility complex class I but lack major histocompatibility complex class II on their surface [44]. They exert an anti-microbial role by dynamically balancing pro- and antiinflammatory responses, secreting anti-microbial peptides and molecules such as indoleamine 2,3-dioxygenase and IL-17, in addition to their autocrine and paracrine functions [51,52].

Bone marrow-derived MSCs (BM-MSCs) have been widely used, followed by umbilical cord-derived MSCs (UC-MSCs) and adiposederived MSCs (AD-MSCs), for cytokine storm rescue. Apart from stromal vascular fraction cells and adipose-derived stromal cells (ADSCs), the stromal vascular fraction obtained after lipoaspirate contains endothelial cells, macrophages and pericytes, fulfilling the MSC definition described by the International Society for Cell \& Gene Therapy $[53,54]$. ADSCs have high immunomodulatory, anti-inflammatory, proliferation, differentiation and regenerative potential compared with BM-MSCs [55]. They express fatty acid translocase marker CD36 but lack cell adhesion marker CD106 compared with BM-MSCs [56]. The paracrine effects of hepatocyte growth factor (HGF), vascular endothelial growth factor (VEGF), platelet-derived growth factor (PDGF) and fibroblast growth factor 2 (FGF2) released by ADSCs aid in resolving the lung injury caused by COVID-19 infection by promoting type 2 alveolar cell regeneration and angiogenesis [57]. The immunomodulatory effects of ADSCs are driven primarily by antiinflammatory cytokine IL-10 and conversion of inflammatory macrophage M1 to the anti-inflammatory and wound healing M2 type [55]. The extracellular matrix is maintained by ADSCs by regulating the levels of matrix metalloproteinase and tissue inhibitor matrix metalloproteinase. Ease of harvest, along with higher yield, longer life span and shorter doubling time, makes ADSCs a more preferred source of MSCs compared with BM-MSCs and UC-MSCs.

\section{MSCs in viral infections}

MSCs have been widely used in the management of both infectious and non-infectious etiologies owing to their immunomodulatory and regenerative potential.

\section{Human immunodeficiency virus}

Despite highly active anti-retroviral therapy and reduction in viral load, some HIV patients are vulnerable to opportunistic infections. These patients are categorized as non-immune responders (NIRs) [58]. In a pilot open-label clinical trial, Zhang et al. [59] administered three doses of UC-MSCs to seven NIR patients, and six NIRs served as controls. The results revealed an increase in circulating naive and central memory CD4 T-cell counts along with HIV-1specific interferon $\gamma$ and IL-2 generation. However, MSCs have been shown to reactivate latent HIV in macrophages and T-helper lymphocytes through PI3 kinase and nuclear factor kappa light chain enhancer of activated B-cell pathways using in vitro models [60]. Clinical trials with AD-MSCs (NCT02290041) and UC-MSCs (NCT01213186) are ongoing to evaluate the safety, efficacy and optimal dosage for reconstituting CD4 $\mathrm{T}$ cells. It has been shown that MSCs obtained from HIV patients harbor defective differentiation potential, thereby limiting the usage of autologous MSC transplantation [61]. Further studies are needed to determine the role of MSCs in immune restoration in NIR as well as HIV patients and whether MSCs can be administered as monotherapy or in combination with anti-viral therapy.

\section{Hepatitis B virus}

Liver disease is a major complication of chronic hepatitis B virus (HBV) infection, and orthotopic liver transplantation remains the only therapeutic strategy in end-stage disease, with artificial liver support systems serving as a temporary measure [62]. Although Xie et al. [63] found BM-MSCs to be resistant to HBV infection, Ma et al. [64] showed that BM-MSCs of HBV patients can be a virus reservoir. A single dose of autologous BM-MSCs in 53 patients with liver failure caused by HBV has been shown to be well tolerated, but the improvement is shortlived [65]. Zhong et al. [66] found that BM-MSCs of HBV patients had deranged proliferative capacity. A comparative study to investigate the differentiation ability and resistance to HBV was conducted by Wang et al. [67] in BM-MSCs and AD-MSCs. Both differentiated well into hepatocytes; however, only AD-MSCs were resistant to HBV. Phase 2 clinical trials by Ling et al.(NCT01223664) and Bingliang et al. (NCT01221454) are comparing the safety and efficacy of allogeneic BM-MSC transplantation in liver failure induced by chronic hepatitis in comparison to conventional treatment. In addition, Bingliang et al.are studying the effect of three different dosages of BM-MSCs $\left(2 \times 10^{5}\right.$ cells $/ \mathrm{kg}, 1 \times 10^{6}$ cells $/ \mathrm{kg}$ and $5 \times 10^{6}$ cells $/ \mathrm{kg}$ ) (NCT01322906). Gao et al.are evaluating the role of combination treatment with UC-MSCs and plasma exchange therapy for acute-on-chronic liver failure (NCT01724398) and investigating the short- and long-term outcomes of autologous BM-MSC transplantation in liver failure patients (NCT00956891). Jasirwan et al.(NCT04357600) and Fan et al. (NCT03826433) are evaluating the safety and efficacy of UC-MSCs in patients with liver failure due to chronic HBV infection. Multi-centric clinical trials with MSCs from different sources and long-term followup will help to obtain clarity on the safety and efficacy of MSCs in liver failure secondary to chronic HBV infection.

\section{Clinical trials for cell therapy in COVID-19 management}

The initial reports of stem cells as a therapeutic strategy for COVID-19 came from China, with the injection of human UC-MSCs into a 65-yearold woman on ventilation. After the second injection of 50 million MSCs, the patient showed improvement and received three infusions of MSCs 3 days apart. Serum bilirubin, liver function enzymes and C-reactive protein levels decreased, and CD3+ T cells, $C D 4+T$ cells and CD8+ T cells increased to normal levels. The patient was weaned from the ventilator and 2 days after the third infusion tested negative for COVID-19 [68]. Seven more patients (one critically ill, four severely ill, two mildly ill) were injected intravenously with clinical-grade MSCs, and three severely ill COVID-19 patients were treated with placebo in a hospital in Beijing, China [69]. They were given a single injection of $1 \times 10^{6}$ stem cells $/ \mathrm{kg}$ of weight and followed up for 14 days. Lung function improved on the second day, and C-reactive protein, CXCR3+CD4+T cells, CXCR3+CD8+T cells and CXCR3 plus natural killer cells decreased over a week post-injection. Regulatory dendritic cells CD14+CD11c+CD11b and IL-10 increased in the MSCinjected group. The study also revealed that MSCs did not express ACE-2 or transmembrane protease serine 2 . The plausible mechanism by which the MSCs might have worked was by reducing the molecules that induce inflammation and triggering those that dampen inflammation.

The US Food and Drug Administration has allowed the use of MSCs as an investigational drug [70-72]. Over 50 clinical trials using MSCs or their products for COVID-19 are registered at ClinicalTrials. gov. The highest number of ongoing clinical trials are in the USA (18), followed by China (nine). Intravenous injection of MSCs ranging from $0.5 \times 10^{6}$ cells $/ \mathrm{kg}$ to $750 \times 10^{6}$ cells $/ \mathrm{kg}$ is being used in these clinical trials. Three trials have employed MSC-derived exosome vesicles, of which two used aerosols. Most trials are using MSCs derived from allogeneic umbilical cord (twenty one), followed by bone marrow (ten), adipose (ten), Wharton's jelly (six), dental pulp (two), olfactory mucosa (one) and unknown (six). Mount Sinai Hospital injected MSCs obtained from Mesoblast Ltd, an Australian biotech company, 
in 12 ventilator-dependent ARDS patients, with encouraging results. This prompted a randomized, double-blind, placebo-controlled trial with 300 patients $[73,74]$ using an intravenous infusion of BM-MSCs $2 \times 10^{6}$ cells $/ \mathrm{kg}$ (NCT4371393). Mesoblast is extending the use of MSCs to children from 2 months to 15 years of age [75]. The ongoing clinical trials are listed in Table 1.

Intramuscular injection of placenta-derived mesenchymal-like cells cured six severely ill COVID-19 patients in a trial conducted by Pluristem Therapeutics Inc, an Israel-based biotech firm [76]. A randomized, double-blind, placebo-controlled, multi-center (USA and Israel), parallel assignment phase 2 trial with 140 patients is being conducted by Pluristem Theapeutics Inc, comparing high and multiple doses of intramuscular injections of MSCs $\left(300 \times 10^{6}\right.$ cells $)$ with placebo treatment (NCT04389450). Novellus, Inc, and Citius Pharmaceuticals, Inc, propose to use MSCs derived from reprogrammed messenger RNA induced pluripotent stem cells generated from fibroblasts of a single individual (NoveCite MSCs). A randomized, placebo-controlled, doseinducing study followed by a dose level expansion to assess the safety and efficacy of NoveCite MSCs in subjects with ARDS due to COVID-19 is in the pipeline [77]. An induced pluripotent stem cell bank would help overcome the scarcity or unavailability of MSCs.

Athersys, Inc, completed a phase $1 / 2$ clinical trial of intravenous injection of their innovative product MultiStem in COVID-19 patients [78]. Phase 1, with a small initial dose, confirmed the safety, and phase 2, with a larger dosage, was a double-blind, placebo-controlled, randomized trial. A total of 36 patients were included in the study wherein six patients were treated with a small dose of MultiStem cells, 20 were intravenously injected with $900 \times 10^{6}$ MultiStem cells and 10 were treated with a placebo. The treatment group had lower mortality and lesser intensive care unit days, without any adverse reactions [79]. The group is now conducting a phase $2 / 3$ clinical trial to investigate the safety and efficacy of MultiStem in COVID-19 patients with ARDS (NCT04367077) by recruiting 400 patients. The study will have two arms: experimental and placebo.

Cynata Therapeutics has initiated an open-label, randomized controlled clinical trial to evaluate the safety and efficacy of their Cymerus MSCs. These MSCs are derived from mesenchymal angioblasts. Using their proprietary technology, induced pluripotent stem cells are generated using transgene-, viral- and feeder-free techniques by de-differentiation of donated blood. These stem cells are further differentiated to mesenchymal angioblasts for the derivation of MSCs used in the infusion (NCT02923375). Of the 24 intensive care unit patients recruited, 12 random patients will be infused with Cymerus MSCs in addition to standard of care, and the other 12 receiving standard of care would serve as controls. The endpoint would be improvement in hypoxia at day 7 and safety/tolerability in 28 days [80].

Sanchez-Guijo et al. [81] treated 13 COVID-19 patients with ADMSCs post anti-viral and anti-inflammatory treatment. Two patients received a single dose, 10 received double the dose and another received a single dose of 0.98 cells $/ \mathrm{kg}$ body weight. The clinical analysis revealed improvement in the beneficial immune cell profile, with no adverse effects of the infusion (NCT04348461). Hope Biosciences is conducting three clinical trials using AD-MSCs in an attempt to address the dose-scaling effect of MSC infusion, starting with $50 \times 10^{6}$ cells $/ \mathrm{kg}$ and going up to $200 \times 10^{6}$ cells $/ \mathrm{kg}$ over $4-5$ intravenous infusions, and to evaluate safety and efficacy in a phase 2 trial (NCT04362189, NCT04349631, NCT04348435). The START study (STem cells for ARDS Treatment) recently published a phase 2 safety administration trial with a single dose of intravenous MSCs [82]. Bari et al. [83] and Sanap et al. [84] advocate the use of MSC secretome as a cell-free treatment modality for COVID-19 patients with ARDS.

\section{Protective mechanisms of MSCs in ARDS}

Migration of MSCs is stimulated by the pro-inflammatory marker TNF $\alpha$ [85] and by the binding of ligands CD106 and CD62E with integrin $\alpha 4 / \beta 1(C D 49 \delta / C D 29)$ and CD44 receptors, respectively $[86,87]$. Trophic factors such as epithelial growth factor, transforming growth factors $\alpha$ and $\beta$, basic FGF2, HGF, insulin-like growth factor 1, VEGF, stem cell factor and stem cell-derived factor 1 and immunomodulatory factors such as prostaglandin E2, inducible nitric oxide synthase, indoleamine 2,3-dioxygenase, CCL2, IL-10 and IL-6 are some of the molecules released by MSCs $[88,89]$. The cytokine secretion profile of dendritic cells and macrophages is modulated by MSCs [90]. The anti-proliferative properties of MSCs play a role in limiting the proliferation of $\mathrm{T}$ lymphocytes, $\mathrm{B}$ cells, natural killer cells and microglial cells [91]. MSCs have been successfully transplanted in graft-versus-host disease and in multiple system atrophy [92,93].

MSCs have immunomodulatory functions, direct cell-to-cell interactions and secrete growth factors and extracellular vesicles. During inflammation, impaired barrier properties of epithelial cells are associated with an increase in the permeability of endothelial cells in the lungs [94]. It has been shown that intratracheal MSC administration in lipopolysaccharide-induced inflammatory conditions in mouse models leads to a reduction in inflammation [95]. This study also demonstrated that through the paracrine process MSCs can induce IL-10 via prostaglandin E2 and other secretory factors, such as granulocyte-macrophage colony-stimulating fact and granulocyte colonystimulating factor, which help to recover the barrier properties of the lungs. Additionally, MSCs secrete anti-inflammatory factors IL-10 and IL-4 and suppress the activation of lymphocytes and inflammatory cytokines IL-1- $\alpha$, IL-1- $\beta$, IL-6, IL-17, TNF $\alpha$, TNF $\gamma$ and interferon $\gamma$ [96]. It has also been described that MSCs reduce the excessive secretion of neutrophil extracellular traps at the site of infection, thereby preventing further damage to lung tissues [97]. MSCs have the ability to reduce the excessive production of neutrophils that causes tissue damage and increase neutrophil-mediated phagocytosis in bacterial infections [98]. MSCs play a role in differentiating macrophages into M1 and M2 phenotypes. M1 activates phagocytosis, which has a proinflammatory function and aids in bacterial clearance, and M2 supports tissue repair by resolving inflammation at the infection site [99,100]. MSCs also suppress the proliferation of effector T cells and promote regulatory $\mathrm{T}$ cells, thereby reducing the immune response and resolving lung damage in ARDS [101].

In a sepsis mouse model, MSCs were shown to have transcriptional responses via the downregulation of Toll-like receptor-mediated nuclear factor kappa light chain enhancer of activated B cells and along with a simultaneous upregulation of the nuclear factor of activated $T$ cells, calcium and calcineurin gene families regulating the transcription of cytokine genes [102]. In a lipopolysaccharideinduced acute lung injury mouse model, BM-MSCs established cellto-cell contact with connexin 43 gap junction channels. The attached MSCs released mitochondria-containing microvesicles into alveolar epithelial cells. The mitochondrial transfer increased adenosine triphosphate concentrations in epithelial cells, thereby repairing alveolar epithelial and endothelial barriers in acute lung injury [103]. In addition, an Escherichia coli pneumonia model demonstrated that mitochondrial transfer from MSCs to macrophages partially occurs through tunneling nanotube-like structures [104]. The mitochondrial transfer enhances phagocytic activity, which establishes a mechanism for anti-microbial effect through cell-to-cell contact. MSCs also play a paracrine role by secreting soluble molecules.

In a rat ventilator-induced lung injury model, the MSC secretome (MSC-conditioned medium) reversed the lung injury via keratinocyte growth factor (KGF). KGF repairs epithelial cells by enhancing Na-KATPase, anti-inflammatory cytokine (IL- $1 \alpha$, matrix metallopeptidase 9) and macrophage activity via granulocyte-macrophage colonystimulating factor $[105,106]$. Overexpression of certain MSC factors, such as PDGF $\beta$, VEGF, basic FGF, angiogenin 1 and PDGF, induces cell proliferation and brings about lung repair [107]. In various studies, the overexpression of angiogenin 1, KGF, ACE-2, CXCR4 and HGF has reduced endotoxin-induced lung injury, edema formation, collagen 


\begin{tabular}{|c|c|c|c|c|c|c|c|c|c|}
\hline \multirow[t]{2}{*}{ Sl. No. } & \multirow[t]{2}{*}{ Clinical trial no. } & \multirow{2}{*}{$\begin{array}{l}\text { Number } \\
\text { of patients }\end{array}$} & \multicolumn{6}{|c|}{ Study } & \multirow[t]{2}{*}{ Source of biological material } \\
\hline & & & Arms & Type & Phase & Design & Purpose & Country & \\
\hline 1 & NCT04276987 & 30 & $\begin{array}{l}\text { Conventional plus aerosol inhalation of MSC- } \\
\text { derived exosomes }\end{array}$ & Interventional & I & Single group treatment & Treatment & Spain & Allogeneic AD-MSC exosomes \\
\hline 2 & NCT04400032 & 9 & $\begin{array}{l}\text { Experimental with escalating dose }\left(25 \times 10^{6}\right. \\
\left.\text { cells } / \mathrm{kg}, 50 \times 10^{6} \text { cells } / \mathrm{kg}, 90 \times 10^{6} \mathrm{cells} / \mathrm{kg}\right) \\
\text { and three infusions }\end{array}$ & Interventional & I & Single group treatment & Dose-escalating safety & Canada & BM-MSCs \\
\hline 3 & NCT4341610 & 40 & $\begin{array}{l}\text { Experimental: } 100 \times 10^{6} \text { cells } / \mathrm{kg} \\
\text { Control: normal saline }\end{array}$ & Interventional & I-II & $\begin{array}{l}\text { Double-blind, randomized, pla- } \\
\text { cebo-controlled }\end{array}$ & Treatment & Denmark & Allogeneic AD-MSCs \\
\hline 4 & NCT04445220 & 24 & $\begin{array}{l}\text { Experimental: } 1 \text {, low dose, } 250 \times 10^{6} \text { cells } / \mathrm{kg} \\
\text { 2, high dose, } 750 \times 10^{6} \text { cells } / \mathrm{kg} \\
\text { Control: sham } \\
\text { In patients with acute kidney injury, MSC infu- } \\
\text { sion by integration with continuous renal } \\
\text { replacement therapy }\end{array}$ & Interventional & I-II & $\begin{array}{l}\text { Randomized, multi-center, dou- } \\
\text { ble-blind, sham-controlled }\end{array}$ & $\begin{array}{l}\text { Safety, treatment and } \\
\text { tolerability }\end{array}$ & USA & Allogeneic MSC \\
\hline 5 & NCT04466098 & 30 & $\begin{array}{l}\text { Experimental: } 300 \times 10^{6} \text { cells } / \mathrm{kg} \text { (three times) } \\
\text { Control: placebo }\end{array}$ & Interventional & II & $\begin{array}{l}\text { Randomized, multi-center, pla- } \\
\text { cebo-controlled }\end{array}$ & Treatment & USA & Allogeneic MSC \\
\hline 6 & NCT04299152 & 20 & $\begin{array}{l}\text { Experimental: stem cell educator therapy } \\
\text { Control: conventional therapy } \\
\text { Patient blood separated by apheresis, and } \\
\text { patient immune cells co-cultured with cord } \\
\text { blood stem cells, followed by putting the edu- } \\
\text { cator immune cells back in patients }\end{array}$ & Interventional & II & $\begin{array}{l}\text { Partially masked and single } \\
\text { center }\end{array}$ & $\begin{array}{l}\text { Safety, feasibility and } \\
\text { efficacy }\end{array}$ & USA & Human multipotent UC-MSCs \\
\hline 7 & NCT04333368 & 40 & $\begin{array}{l}\text { Experimental: } 1 \times 10^{6} \text { cells } / \mathrm{kg} \text { (three times) } \\
\text { Control: normal saline }\end{array}$ & Interventional & I-II & Randomized parallel assignment & Treatment & France & UC Wharton's jelly \\
\hline 8 & NCT04491240 & 90 & $\begin{array}{l}\text { Experimental: 1, exosome inhalation (first type) } \\
2 \text {, exosome inhalation (second type) } \\
\text { Control: placebo inhalation }\end{array}$ & Interventional & I-II & Randomized parallel assignment & Safety and treatment & Russia & AD-MSCs \\
\hline 9 & NCT04447833 & 9 & $\begin{array}{l}\text { Experimental: } 1 \text {, MSC infusion } 1 \times 10^{6} \text { cells } / \mathrm{kg} \\
2 \text {, MSC infusion } 2 \times 10^{6} \text { cells } / \mathrm{kg}\end{array}$ & Interventional & I & $\begin{array}{l}\text { Open-label dose escalation study } \\
\text { of advanced therapy investiga- } \\
\text { tional medicinal product }\end{array}$ & Safety & Sweden & Allogeneic BM-MSCs \\
\hline 10 & NCT04437823 & 20 & $\begin{array}{l}\text { Experimental: MSC infusion } 5 \times 10^{5} \text { cells } / \mathrm{kg} \\
\text { (three times) } \\
\text { Control: standard of care }\end{array}$ & Interventional & II & Randomized open-label & Treatment & Pakistan & UC \\
\hline 11 & NCT04269525 & 16 & Experimental: $3.3 \times 10^{7}$ cells $/ \mathrm{kg}$ & Interventional & II & Single group assessment & Prevention and treatment & China & UC \\
\hline 12 & NCT04389450 & 140 & $\begin{array}{l}\text { Experimental: high dose (once and twice) and } \\
\text { low dose (once) MSC infusion } \\
\text { Control: placebo infusion (once and twice) }\end{array}$ & Interventional & II & $\begin{array}{l}\text { Randomized, multi-center, dou- } \\
\text { ble-blind }\end{array}$ & Treatment & Israel & $\begin{array}{l}\text { Placental mesenchymal-like } \\
\text { adherent stromal cells }\end{array}$ \\
\hline 13 & NCT03042143 & $\begin{array}{l}18 \text { (phase } 1 \text { ) and } 60 \\
\text { (phase 2) }\end{array}$ & $\begin{array}{l}\text { Experimental: } 1 \text {, CD } 362 \text {-enriched MSCs, } \\
100 \times 10^{6} \mathrm{cells} / \mathrm{kg}, 200 \times 10^{6} \mathrm{cells} / \mathrm{kg} \text {, } \\
400 \times 10^{6} \mathrm{cells} / \mathrm{kg} \\
2 \text {, highest dose of experimental arm } 1 \text {. } \\
\text { Control: placebo }\end{array}$ & Interventional & I-II & $\begin{array}{l}\text { Open-label dose escalation pilot } \\
\text { study. Phase } 1 \text { double blind, } \\
\text { randomized, placebo con- } \\
\text { trolled. Phase } 2 \text { clinical trial }\end{array}$ & Treatment & UK & UC \\
\hline 14 & NCT04361942 & 24 & $\begin{array}{l}\text { Experimental: } 1 \times 10^{6} \text { cells } / \mathrm{kg} \\
\text { Control: placebo }\end{array}$ & Interventional & II & $\begin{array}{l}\text { Double-blind, randomized, pla- } \\
\text { cebo-controlled }\end{array}$ & Treatment & Spain & Allogeneic MSC \\
\hline 15 & NCT04398303 & 70 & $\begin{array}{l}\text { Experimental: } 1 \text {, MSC infusion } 1 \times 10^{6} \text { cells } / \mathrm{kg} \\
\text { plus conventional treatment } \\
2 \text {, conditioned medium plus conventional } \\
\text { treatment } \\
\text { Control: conventional treatment plus placebo }\end{array}$ & Interventional & I-II & Randomized, placebo-controlled & Safety and treatment & USA & Allogeneic human UC-MSCS \\
\hline 16 & NCT04467047 & 10 & Experimental: MSC infusion $1 \times 10^{6}$ cells $/ \mathrm{kg}$ & Interventional & I & $\begin{array}{l}\text { Open-label, single group } \\
\text { assignment }\end{array}$ & Safety and feasibility & Brazil & BM-MSCs \\
\hline
\end{tabular}




\begin{tabular}{|c|c|c|}
\hline Sl. No. & Clinical trial no. & $\begin{array}{l}\text { Numl } \\
\text { of pat }\end{array}$ \\
\hline 17 & NCT04392778 & 30 \\
\hline 18 & NCT04390139 & 30 \\
\hline 19 & NCT04492501 & 600 \\
\hline 20 & NCT04345601 & 30 \\
\hline 21 & NCT4377334 & 40 \\
\hline 22 & NCT04397796 & 45 \\
\hline 23 & NCT04494386 & 60 \\
\hline 24 & NCT04371393 & 300 \\
\hline 25 & NCT04452097 & 9 \\
\hline 26 & NCT04390152 & 40 \\
\hline 27 & NCT04362189 & 100 \\
\hline 28 & NCT04348461 & 100 \\
\hline 29 & NCT04371601 & 60 \\
\hline 30 & NCT04461925 & 30 \\
\hline 31 & NCT04355728 & 24 \\
\hline
\end{tabular}

Number

Arms

Experimental: MSC infusion $3 \times 10^{6} \mathrm{cells} / \mathrm{kg}$

(three times) with ventilator

Sham comparator
Saline infusion (three times) with ventilator

Untreated without ventilator

Experimental: MSC infusion $1 \times 10^{6} \mathrm{cells} / \mathrm{kg}$

Placebo comparator

Experimental: 1, therapeutic plasma exchange

2 , therapeutic plasma exchange plus MSC infu-

sion $2 \times 10^{6}$ cells $/ \mathrm{kg}$ or remdesivir

3 , MSC infusion $2 \times 10^{6}$ cells $/ \mathrm{kg}$ and/or remde-

sivir and/or tocilizumab (all alone or in

combination)

Experimental: MSC infusion $1 \times 10^{8}$ cells $/ \mathrm{kg}$

(twice)

Control: standard of care

Experimental: MSC infusion

Control: no intervention

Experimental: MSC infusio

Control: placebo
Experimental: 1 , MSC infusion $100 \times 10^{6}$ cells $/ \mathrm{kg}$ Interventional I-II $\begin{gathered}\text { cebo-controlled } \\ \text { Open-label, non-controlled trial Safety and treatment }\end{gathered}$ (phase 1, open-label, one or two infusions)

2 , MSC infusion (randomized, one or two infu-

sions)

3, placebo infusion (one or two infusions)

Experimental: MSC infusion $2 \times 10^{6}$ cells $/ \mathrm{kg}$ (remestemcel-L) plus standard of treatment Control: placebo plus standard of treatment Experimental: MSC infusion $0.5 \times 10^{6}$ cells $/ \mathrm{kg}$, $1 \times 10^{6}$ cells $/ \mathrm{kg}, 1.5 \times 10^{6}$ cells $/ \mathrm{kg}, \mathrm{BX}-\mathrm{U} 001$ Experimental: MSC infusion $50 \times 10^{6}$ cells $/ \mathrm{kg}$ (twice) plus hydroxychloroquine plus lopina-
vir/ritonavir or azithromycin

Control: placebo plus hydroxychloroquine plus Control: placebo plus hydroxychloro
lopinavir/ritonavir or azithromycin

lopinavir/ritonavir or azithromycin
Experimental: MSC infusion $100 \times 10^{6} \mathrm{cells} / \mathrm{kg}$

Experimental: MSC

Control: saline (four infusions)

Experimental: MSC infusion $1.5 \times 10^{6}$ cells/kg

(twice)

Control: standard of treatment

Experimental: MSC infusion $1 \times 10^{6}$ cells/kg (four Interventional I Randomized, parallel assign- $\quad$ Safety and treatment infusions) plus standard of care

Control: standard of care

Experimental: MSC infusion $1 \times 10^{6}$ cells $/ \mathrm{kg}$

(twice) plus standard of care

Control: standard of care

Experimental: MSC infusion $100 \times 10^{6} \mathrm{cells} / \mathrm{kg}$

(twice) plus standard of care plus heparin

Control: standard of care plus vehicle plus

heparin

Randomized, placebo-con-
Source of biological material

Purpose

Country

$\begin{array}{lllll}\text { Interventional I-II } & \begin{array}{c}\text { Randomized, double-blind, par- } \\ \text { allel assignment }\end{array} & \text { Treatment } & \text { Turkey } & \text { Allogeneic UC } \\ \text { Interventional I-II } & \begin{array}{c}\text { Randomized, double-blind, par- } \\ \text { allel assignment }\end{array} & \text { Safety and treatment } & \text { Spain } & \text { Wharton's jelly MSC }\end{array}$

$\begin{array}{llll}\text { allel assignment } & \text { Pakistan } & \text { BM-MSCs }\end{array}$

factorial assignment, case-

-control study

Interventional I Randomized, open-label, parallel Treatment assignment

USA BM-MSCS

Germany BM-MSCs

USA BM-MSCS

USA UC-MSCS

trolled trial

Interventional III Randomized, double-blind, par- Safety and treatment allel assignment, placebocontrolled

Interventional I Non-randomized, open-label, Safety

single arm, dose-escalating

Interventional I-II Randomized, double-blind, par- Safety and treatment allel assignment

Interventional II Randomized, double-blind, pla- Safety and treatment cebo-controlled

Randomized, two-treatment, Safety and treatment multi-center, controlled

ment, open-label

Interventional I-II Non-randomized, open-label, Safety and treatment parallel assignment

Interventional I-II Randomized, double-blind, par- Safety and treatment allel assignment 
Table 1 (Continued)

\begin{tabular}{|c|c|c|c|c|c|c|c|c|c|}
\hline \multirow[t]{2}{*}{ Sl. No. } & \multirow[t]{2}{*}{ Clinical trial no. } & \multirow{2}{*}{$\begin{array}{l}\text { Number } \\
\text { of patients }\end{array}$} & \multicolumn{6}{|c|}{ Study } & \multirow[t]{2}{*}{ Source of biologic } \\
\hline & & & Arms & Type & Phase & Design & Purpose & Country & \\
\hline 32 & NCT04490486 & 21 & $\begin{array}{l}\text { Experimental: MSC infusion } 100 \times 10^{6} \text { cells } / \mathrm{kg} \\
\text { (twice) } \\
\text { Control: placebo }\end{array}$ & Interventional & I & $\begin{array}{l}\text { Randomized, double-blind, pla- } \\
\text { cebo-controlled }\end{array}$ & Safety and treatment & USA & UC \\
\hline 33 & NCT04302519 & 24 & $\begin{array}{l}\text { Experimental: MSC infusion } 1 \times 10^{6} \text { cells } / \mathrm{kg} \\
\text { (dose scaling) }\end{array}$ & Interventional & I & $\begin{array}{l}\text { Open-label, single center, single } \\
\text { arm }\end{array}$ & Safety and treatment & China & Dental pulp \\
\hline 34 & NCT04352803 & 20 & $\begin{array}{l}\text { Experimental: MSC infusion } 5 \times 10^{5} \text { cells } / \mathrm{kg} \text { plus } \\
\text { standard of care } \\
\text { Control: standard of care }\end{array}$ & Interventional & I & $\begin{array}{l}\text { Non-randomized, open-label, } \\
\text { sequential assignment, } \\
\text { unmatched control }\end{array}$ & Safety and treatment & USA & Adipose tissue \\
\hline 35 & NCT04457609 & 40 & $\begin{array}{l}\text { Experimental: MSC infusion } 1 \times 10^{6} \text { cells } / \mathrm{kg} \text { plus } \\
\text { standard of treatment } \\
\text { Control: standard of treatment }\end{array}$ & Interventional & I & $\begin{array}{l}\text { Randomized, double-blind, par- } \\
\text { allel assignment, controlled } \\
\text { trial }\end{array}$ & Safety and treatment & Indonesia & UC \\
\hline 36 & NCT04349631 & 56 & Experimental: MSC infusion (five times) & Interventional & II & $\begin{array}{l}\text { Open-label, single center clinical } \\
\text { trial }\end{array}$ & Safety and treatment & USA & Adipose tissue \\
\hline 37 & NCT04428801 & 200 & $\begin{array}{l}\text { Experimental: MSC infusion } 200 \times 10^{6} \text { cells } / \mathrm{kg} \\
\text { (three times) } \\
\text { Control: placebo }\end{array}$ & Interventional & II & $\begin{array}{l}\text { Randomized, double-blind, } \\
\text { multi-center, placebo- } \\
\text { controlled }\end{array}$ & Treatment & USA & Adipose tissue \\
\hline 38 & NCT04339660 & 30 & $\begin{array}{l}\text { Experimental: MSC infusion } 1 \times 10^{6} \text { cells } / \mathrm{kg} \text { plus } \\
\text { standard of treatment } \\
\text { Control: placebo plus standard of treatment }\end{array}$ & Interventional & II-III & $\begin{array}{l}\text { Randomized, double-blind, par- } \\
\text { allel assignment }\end{array}$ & Treatment & China & UC \\
\hline 39 & NCT04366063 & 60 & $\begin{array}{l}\text { Experimental: } 1 \text {, MSC infusion } 100 \times 10^{6} \text { cells } / \mathrm{kg} \\
\text { (twice) } \\
\text { 2, MSC infusion } 100 \times 10^{6} \text { cells } / \mathrm{kg} \text { (twice) plus } \\
\text { exosome vesicles (two infusions) } \\
\text { Control: standard of treatment }\end{array}$ & Interventional & II & $\begin{array}{l}\text { Randomized, parallel } \\
\text { assignment }\end{array}$ & Safety and treatment & Iran & NA \\
\hline 40 & NCT04348435 & 100 & $\begin{array}{l}\text { Experimental: } 1 \text {, MSC infusion } 200 \times 10^{6} \text { cells } / \mathrm{kg} \\
\text { (five times) } \\
2 \text {, MSC infusion } 100 \times 10^{6} \text { cells } / \mathrm{kg} \text { (five times) } \\
3 \text {, MSC infusion } 50 \times 10^{6} \text { cells } / \mathrm{kg} \text { (five times) } \\
\text { Control: placebo (five infusions) }\end{array}$ & Interventional & I-II & $\begin{array}{l}\text { Randomized, double-blind, pla- } \\
\text { cebo-controlled }\end{array}$ & Safety and treatment & USA & Adipose tissue \\
\hline 41 & NCT04382547 & 40 & $\begin{array}{l}\text { Experimental: MSC infusion plus standard of } \\
\text { treatment } \\
\text { Control: standard of treatment }\end{array}$ & Interventional & II & $\begin{array}{l}\text { Non-randomized, parallel } \\
\text { assignment, open-label }\end{array}$ & & Belarus & Olfactory mucos \\
\hline 42 & NCT04273646 & 48 & $\begin{array}{l}\text { Experimental: MSC infusion } 0.5 \times 10^{6} \text { cells } / \mathrm{kg} \\
\text { (four times) plus standard of treatment } \\
\text { Control: placebo plus standard of treatment }\end{array}$ & Interventional & $\mathrm{I}-\mathrm{II}$ & $\begin{array}{l}\text { Randomized, parallel assign- } \\
\text { ment, open-label }\end{array}$ & Safety and treatment & China & UC \\
\hline 43 & NCT04288102 & 100 & $\begin{array}{l}\text { Experimental: MSC infusion } 4 \times 10^{7} \text { cells } / \mathrm{kg} \\
\text { (three times) plus standard of treatment } \\
\text { Control: placebo plus standard of treatment }\end{array}$ & Interventional & II & $\begin{array}{l}\text { Randomized, multi-center, dou- } \\
\text { ble-blind, placebo-control }\end{array}$ & Safety and treatment & China & UC \\
\hline 44 & NCT04346368 & 20 & $\begin{array}{l}\text { Experimental: MSC infusion } 1 \times 10^{6} \text { cells } / \mathrm{kg} \text { plus } \\
\text { standard of treatment } \\
\text { Control: placebo plus standard of treatment }\end{array}$ & Interventional & I-II & $\begin{array}{l}\text { Randomized, parallel assign- } \\
\text { ment, open-label }\end{array}$ & Safety and treatment & China & BM \\
\hline 45 & NCT04336254 & 20 & $\begin{array}{l}\text { Experimental: MSC infusion } 3 \times 10^{7} \text { cells } / \mathrm{kg} \\
\text { (three times) plus standard of treatment } \\
\text { Control: saline plus standard of treatment }\end{array}$ & Interventional & I-II & $\begin{array}{l}\text { Randomized, parallel assign- } \\
\text { ment, open-label }\end{array}$ & Safety and treatment & China & Dental pulp \\
\hline 46 & NCT04313322 & 5 & Experimental: MSC infusion & Interventional & I & Open-label, direct study & Safety and treatment & Jordan & Wharton's jelly \\
\hline 47 & NCT04252118 & 20 & $\begin{array}{l}\text { Experimental: MSC infusion } 3 \times 10^{7} \text { cells } / \mathrm{kg} \text { plus } \\
\text { standard of treatment } \\
\text { Control: standard of treatment }\end{array}$ & Interventional & I & $\begin{array}{r}\text { Non-randomized, parallel } \\
\text { assignment, open-label }\end{array}$ & Safety and treatment & China & NA \\
\hline 48 & NCT04366271 & 106 & $\begin{array}{l}\text { Experimental: MSC infusion } \\
\text { Control: standard of treatment }\end{array}$ & Interventional & II & $\begin{array}{l}\text { Randomized, multi-center, par- } \\
\text { allel assignment, open-label }\end{array}$ & Treatment & Spain & UC \\
\hline 49 & NCT04366323 & 26 & $\begin{array}{l}\text { Experimental: MSC infusion } 80 \times 10^{6} \text { cells } / \mathrm{kg} \\
\text { (twice) }\end{array}$ & Interventional & I-II & $\begin{array}{l}\text { Randomized, multi-center, par- } \\
\text { allel assignment, open-label }\end{array}$ & Safety and treatment & Spain & Adipose tissue \\
\hline
\end{tabular}




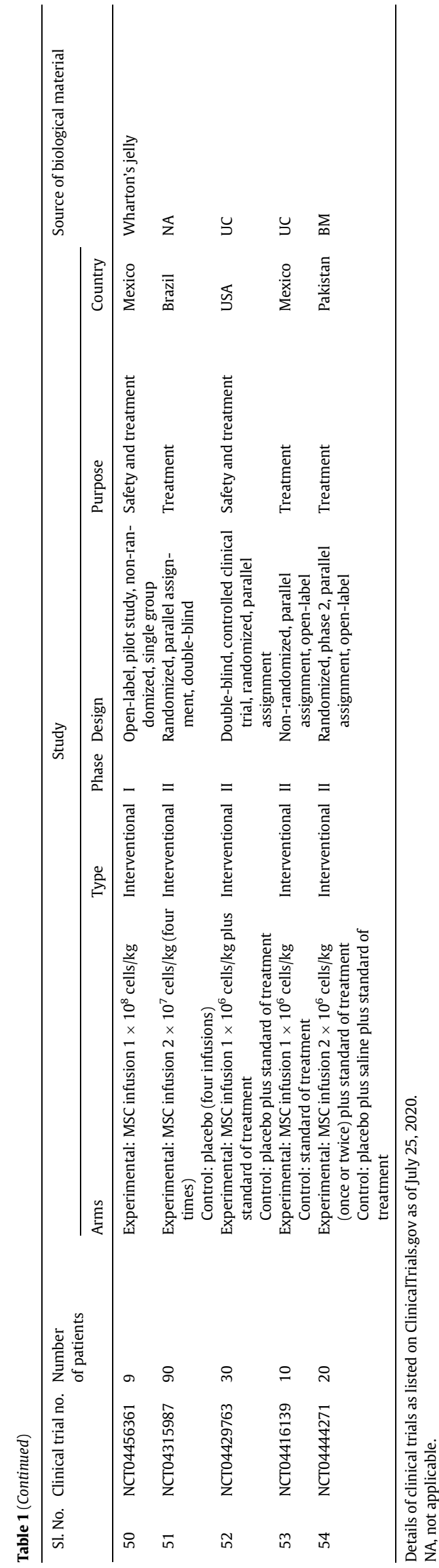

depositionandfibrosis, inadditiontoenhancingthechemotacticandantiinflammatory properties of MSCs [105,108-111]. The plausible mechanismbywhichMSCsresolveARDSisdepictedschematicallyinFigure2.

Experimental and pre-clinical evidence of the benefits of MSCs in immunomodulation of respiratory virus-induced lung injury is available, which may be helpful in the treatment of COVID-19. UC-MSCs are able to restore alveolar epithelial cell functions, as seen by increased alveolar fluid clearance and decreased protein permeability, in avian influenza virus (H5N1) lung injuries in mouse models [112]. MSCs are resistant to viral infections, and recently it has been established that intrinsically expressed interferon-stimulated genes (ISGs) protect stem cells against viral infection [113]. This study demonstrated that induction of intrinsic ISGs in human MSCs constitutively increased the expression of anti-virals (IFI6, ISG15, CCL2, SAT1, PMAIP1 and interferon-induced transmembrane protein 1 [IFITM1]). With regard to anti-viral mechanism, the IFITM family plays a major role in preventing the virus from crossing the lipid bilayer of cells. It has been demonstrated that IFITM prevents the entry of various viruses, including Ebola virus, dengue virus, influenza A virus, Rift Valley fever virus, reovirus and SARS-CoV, as well as replication in HIV-1 and hepatitis C virus [114,115]. Interestingly, it has been shown that SARS-CoV virus internalization is prevented by the host cell receptor ACE-2 in IFITM-expressing cells [114]. In the lungs, the ACE-2 receptor is expressed in alveolar type II cells and endothelial cells, and these cells play a role in preventing virus entry and reducing fibrosis and have anti-inflammatory and endothelial protective effects [116-118].

The COVID-19 mortality rate is higher in patients who have preexisting systemic diseases, such as diabetes, renal disease and hypertension. In these conditions, the ACE-2 receptor plays an important role, as it is a major enzyme in the renin-angiotensin system, which has been localized in the apical surface area and glomeruli of the kidneys and in the acini and islets of the pancreas. In an in vivomouse model, it was demonstrated that an ACE-2 deficiency can cause decreased insulin secretion, leading to diabetes [119]. Plasma ACE-2 levels are lower in chronic kidney disease patients undergoing dialysis [120]. Adult hypertensive rats show decreased expression of ACE2 in the kidneys [121].

The potential benefits of overexpression of ACE- 2 receptors by MSCs in relation to COVID-19 need further exploration. The details regarding the underlying mechanisms involved in resolving COVID19 in patients with infusion of MSCs are still unknown. The authors have schematically represented the plausible mechanism by which MSCs reduce the adverse effects of ARDS caused by COVID-19 based on the existing knowledge (Figure 3).

\section{Discussion}

The emergence of the COVID-19 pandemic and its sequelae have prompted clinicians and researchers to explore all possible preventive and treatment modalities since existing strategies target symptoms, rather than the underlying pathology. Anti-virals, pulmonary and renal support systems and immunomodulators are being used to treat the cytokine storm, which causes respiratory depression and multi-organ dysfunction. Until effective vaccines and specific treatment options are available, the high infectivity rate of COVID-19 makes limiting disease progression a challenge. MSCs serve as a potential therapeutic candidate for combating the cytokine storm owing to their primordial cell lineage and multi-potent functions, such as immunomodulation and anti-inflammatory activity, and their ability to secrete various growth factors and soluble vesicles. Encouraging results from ongoing trials would expand the clinical applicability of MSCs and provide hope for patients suffering with ARDS due to COVID-19 infection.

Clarity is lacking regarding the best source of MSCs, the method of application or mode of infusion of the cells to the patient, the stage of 

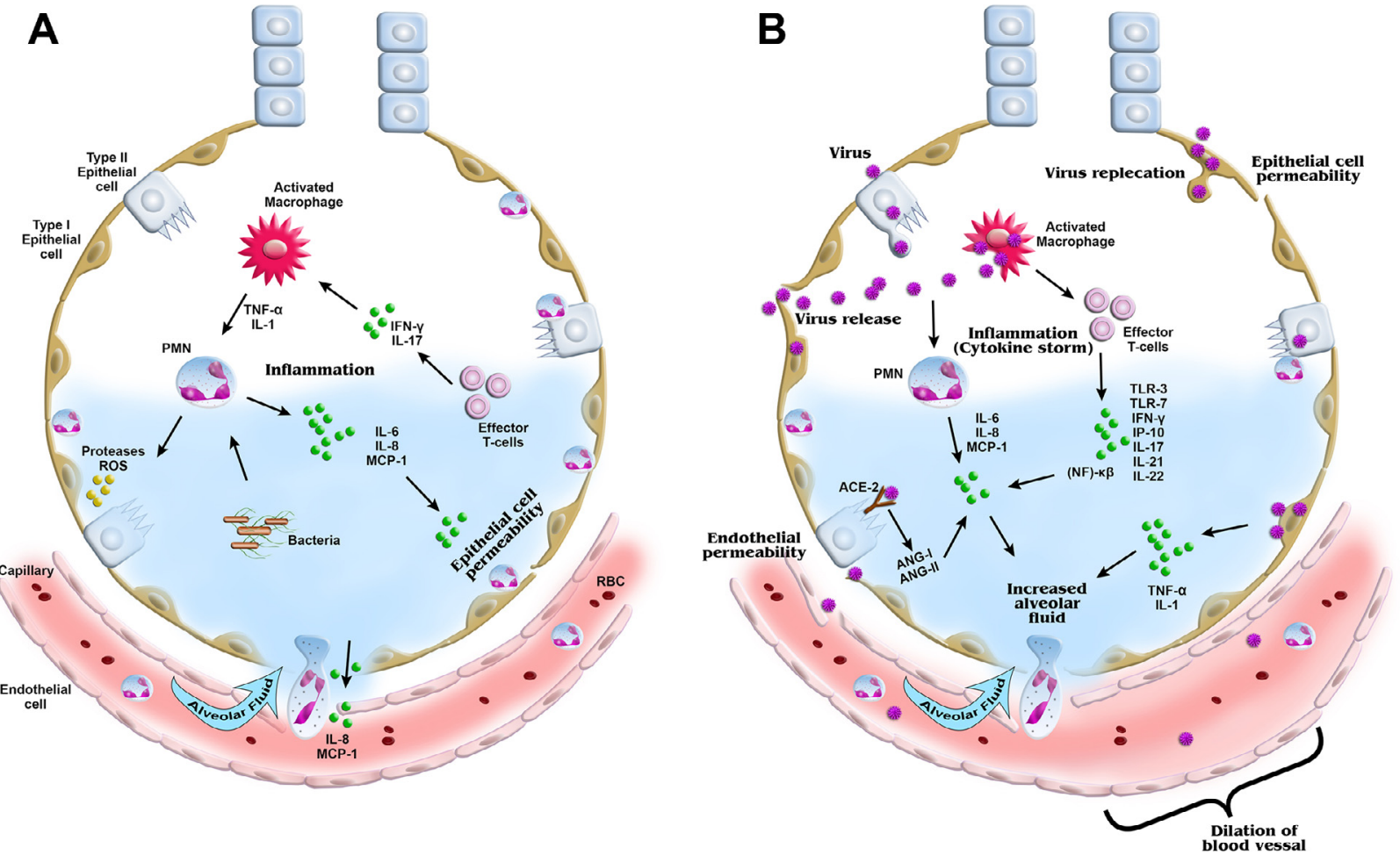

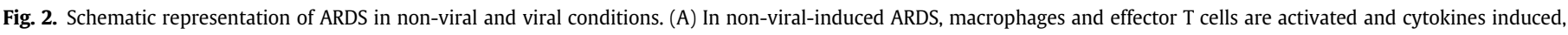

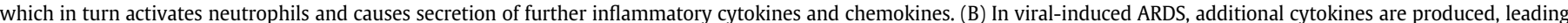

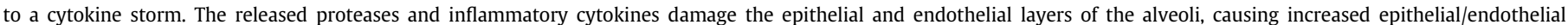

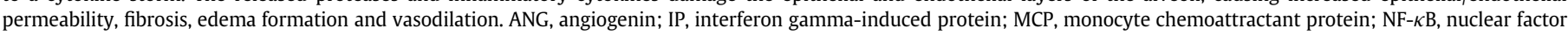

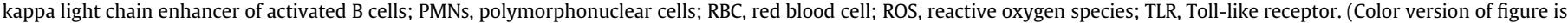
available online).
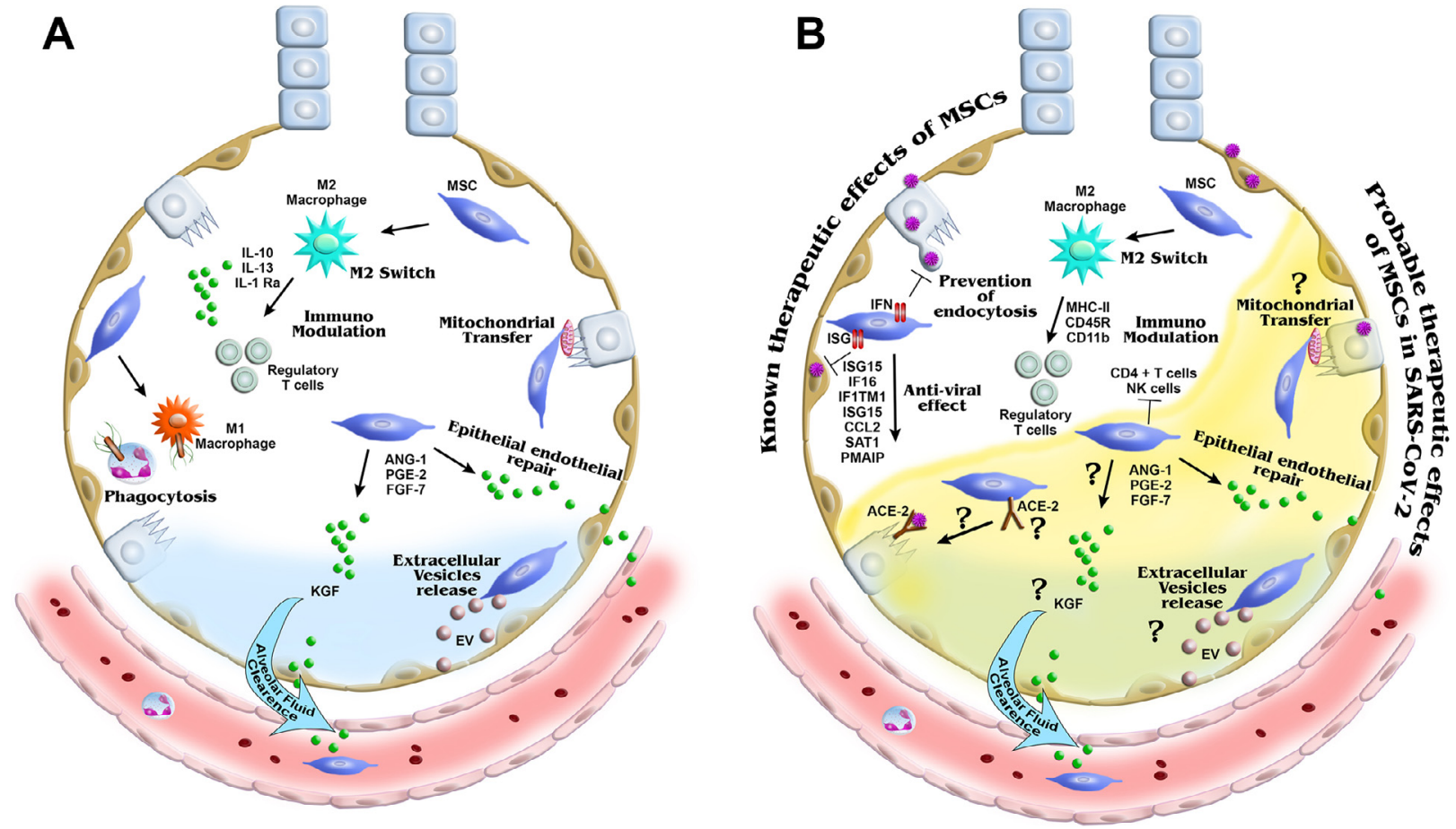

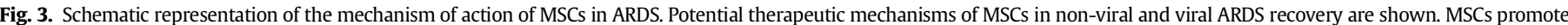

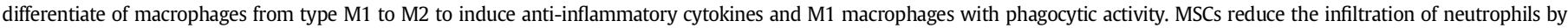

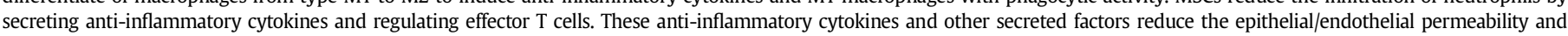

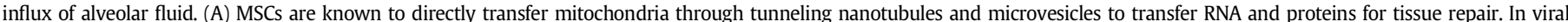

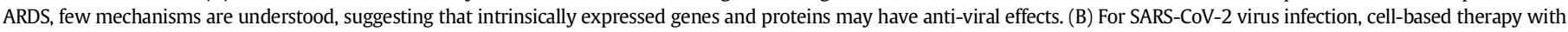

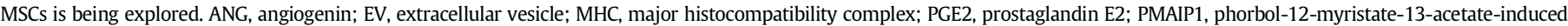
protein 1; PMNs, polymorphonuclear cells; RBC, red blood cell; ROS, reactive oxygen species; SAT, spermidine/spermine N1-acetyltransferase. (Color version of figure is available online). 
disease at which MSCs would work with the highest efficiency, the timeline of results expected post injection, the age group of patients, etc. A combination treatment approach with MSCs and supportive drugs might work synergistically to restrict the infectivity of the virus, in addition to preventing the progression of the infection to a severe form. Another approach may be administration of anti-viral drugs carrying nanoparticles loaded on stem cells with an affinity for ACE-2 receptor-harboring alveolar cells. The means to generate highclinical-grade MSCs is the need of the hour. Apart from cell-based therapy, exosome vesicles as well as the culture secretome of MSC might be explored as an alternative.

Future research toward a better understanding of MSCs resident in lung tissue could pave the way for developing the means to activate host-specific resident stem cells to resolve site-specific ARDS. This would eliminate the need for infusion of allogeneic cell therapy. The results of ongoing clinical trials would help provide guidelines for cell monotherapy or combination therapy with non-cell-based treatment, enabling clinicians worldwide to better manage severely infected COVID-19 patients. With the fear of a second wave of infection looming large, it is a race against time for researchers worldwide to fight the challenge posed by COVID- 19 .

\section{Funding}

No funding was received.

\section{Declaration of Competing Interest}

The authors have no commercial, proprietary or financial interest in the products or companies described in this article.

\section{Author Contributions}

Conception and design of the study: RS and DD. Acquisition of data: MP, KC, CJ and DD. Analysis and interpretation of data: MP, KC, $\mathrm{CJ}$ and DD. Drafting or revising the manuscript: RS, DD, KC, HM, CJ and AG. All authors have approved the final article.

\section{Acknowledgments}

The authors thank Dr K Bhujang Shetty and Dr P Narendra for providing the necessary logistics for this review. The authors also thank the Narayana Nethralaya Foundation for its support. Finally, the authors thank the multimedia team, Narayana Nethralaya Eye Institute, for their help in making the schematic diagrams.

\section{References}

[1] Metcalfe SM. Mesenchymal stem cells and management of COVID-19 pneumonia. Medicine in drug discovery 2020;5:100019.

[2] Majumder M, Mandl K. Early Transmissibility Assessment of a Novel Coronavirus in Wuhan, China. SSRN Electronic Journal 2020.

[3] Sanche S, Lin YT, Xu C, Romero-Severson E, Hengartner N, Ke R. High Contagiousness and Rapid Spread of Severe Acute Respiratory Syndrome Coronavirus 2. Emerg Infect Dis 2020;26(7):1470-7.

[4] Bauch CT, Lloyd-Smith JO, Coffee MP, Galvani AP. Dynamically modeling SARS and other newly emerging respiratory illnesses: past, present, and future. Epidemiology 2005;16(6):791-801.

[5] Killerby ME, Biggs HM, Midgley CM, Gerber SI, Watson JT. Middle East Respiratory Syndrome Coronavirus Transmission. Emerg Infect Dis 2020:26(2):191-8.

[6] Nikbakht R, Baneshi MR, Bahrampour A, Hosseinnataj A. Comparison of methods to Estimate Basic Reproduction Number (R 0) of influenza, Using Canada 2009 and 2017-18 A (H1N1) Data. J Res Med Sci 2019;24:67.

[7] Lovato A, de Filippis C. Clinical Presentation of COVID-19: A Systematic Review Focusing on Upper Airway Symptoms. Ear, nose, \& throat journal 2020. 145561320920762

[8] Shetty R, Ghosh A, Honavar SG, Khamar P, Sethu S. Therapeutic opportunities to manage COVID-19/SARS-CoV-2 infection: Present and future. Indian journal of ophthalmology 2020;68(5):693-702.

[9] Yuki K, Fujiogi M, Koutsogiannaki S. COVID-19 pathophysiology: a review. Clinical immunology 2020;215:108427.
[10] Zaim S, Chong JH, Sankaranarayanan V, Harky A. COVID-19 and Multiorgan Response. Current problems in cardiology 2020;45(8):100618.

[11] Hussain A, Bhowmik B, do Vale Moreira NC. COVID-19 and diabetes: Knowledge in progress. Diabetes research and clinical practice 2020;162:108142.

[12] Shahid Z, Kalayanamitra R, McClafferty B, Kepko D, Ramgobin D, Patel R, Aggarwal CS, Vunnam R, Sahu N, Bhatt D, Jones K, Golamari R, Jain R. COVID-19 and Older Adults: What We Know. Journal of the American Geriatrics Society 2020;68(5):926-9.

[13] Gattinoni L, Coppola S, Cressoni M, Busana M, Rossi S, Chiumello D. COVID-19 Does Not Lead to a "Typical"Acute Respiratory Distress Syndrome. American journal of respiratory and critical care medicine 2020;201(10):1299-300.

[14] McEnery T, Gough C, Costello RW. COVID-19: Respiratory support outside the intensive care unit. The Lancet. Respiratory medicine 2020;8(6):538-9.

[15] Ronco C, Reis T, Husain-Syed F. Management of acute kidney injury in patients with COVID-19. The Lancet. Respiratory medicine 2020;8(7):738-42.

[16] Horby P, Lim WS, Emberson JR, Mafham M, Bell JL, Linsell L, Staplin N, Brightling C. Ustianowski A, Elmahi E, Prudon B, Green C, Felton T, Chadwick D, Rege K, Fegan C, Chappell LC, Faust SN, Jaki T, Jeffery K, Montgomery A, Rowan K, Juszczak E, Baillie JK, Haynes R, Landray MJ. Dexamethasone in Hospitalized Patients with Covid-19-Preliminary Report. The New England journal of medicine 2020.

[17] Cao B, Wang Y, Wen D, Liu W, Wang J, Fan G, Ruan L, Song B, Cai Y, Wei M, Li X Xia J, Chen N, Xiang J, Yu T, Bai T, Xie X, Zhang L, Li C, Yuan Y, Chen H, Li H, Huang H, Tu S, Gong F, Liu Y, Wei Y, Dong C, Zhou F, Gu X, Xu J, Liu Z, Zhang Y, Li H, Shang L, Wang K, Li K, Zhou X, Dong X, Qu Z, Lu S, Hu X, Ruan S, Luo S, Wu J, Peng L, Cheng F, Pan L, Zou J, Jia C, Wang J, Liu X, Wang S, Wu X, Ge Q, He J, Zhan H, Qiu F, Guo L, Huang C, Jaki T, Hayden FG, Horby PW, Zhang D, Wang C. A Tria of Lopinavir-Ritonavir in Adults Hospitalized with Severe COVID-19. The New England journal of medicine 2020;382(19):1787-99.

[18] Huang D, Yu H, Wang T, Yang H, Yao R, Liang Z. Efficacy and safety of umifenovir for coronavirus disease 2019 (COVID-19): A systematic review and meta-analysis. J Med Virol 2020.

[19] Wang Y, Zhang D, Du G, Du R, Zhao J, Jin Y, Fu S, Gao L, Cheng Z, Lu Q, Hu Y, Luo G, Wang K, Lu Y, Li H, Wang S, Ruan S, Yang C, Mei C, Wang Y, Ding D, Wu F, Tang X, Ye X, Ye Y, Liu B, Yang J, Yin W, Wang A, Fan G, Zhou F, Liu Z, Gu X, Xu J, Shang L, Zhang Y, Cao L, Guo T, Wan Y, Qin H, Jiang Y, Jaki T, Hayden FG, Horby PW, Cao B, Wang C. Remdesivir in adults with severe COVID-19: a randomised, double-blind, placebo-controlled, multicentre trial. Lancet 2020;395(10236):1569-78.

[20] Borba M, Val F, Sampaio V, Alexandre M, Melo G, Brito M, et al. Chloroquine diphosphate in two different dosages as adjunctive therapy of hospitalized patients with severe respiratory syndrome in the context of coronavirus (SARSCoV-2) infection: preliminary safety results of a randomized, double-blinded, phase IIb clinical trial (CloroCovid-19 Study). medRxiv 2020.

[21] Gao J, Tian Z, Yang X. Breakthrough: Chloroquine phosphate has shown apparent efficacy in treatment of COVID-19 associated pneumonia in clinical studies. Biosci Trends 2020:14(1):72-3.

[22] Aouba A, Baldolli A, Geffray L, Verdon R, Bergot E, Martin-Silva N, et al. Targeting the inflammatory cascade with anakinra in moderate to severe COVID-19 pneumonia: case series. Ann Rheum Dis 2020;79(10):1381-2.

[23] Huet T, Beaussier H, Voisin O, Jouveshomme S, Dauriat G, Lazareth I, Sacco E, Naccache J-M, Bézie Y, Laplanche S, Le Berre A, Le Pavec J, Salmeron S, Emmerich J, Mourad J-J, Chatellier G, Hayem G. Anakinra for severe forms of COVID-19: a cohort study. The Lancet Rheumatology 2020;2(7):e393-400.

[24] Xu X, Han M, Li T, Sun W, Wang D, Fu B, Zhou Y, Zheng X, Yang Y, Li X, Zhang X Pan A, Wei H. Effective treatment of severe COVID-19 patients with tocilizumab. Proc Natl Acad Sci U S A 2020;117(20):10970-5.

[25] Gaspari V, Zengarini C, Greco S, Vangeli V, Mastroianni A. Side effects of ruxolitinib in patients with SARS-CoV-2 infection: Two case reports. Int J Antimicrob Agents 2020;56(2):106023.

[26] Rizk JG, Kalantar-Zadeh K, Mehra MR, Lavie CJ, Rizk Y, Forthal DN. PharmacoImmunomodulatory Therapy in COVID-19. Drugs 2020;80(13):1267-92.

[27] Murphy M, Estcourt L, Grant-Casey J, Dzik S. International Survey of Trials of Convalescent Plasma to Treat COVID-19 Infection. Transfus Med Rev 2020;34 (3):151-7.

[28] Yigenoglu TN, Hacibekiroglu T, Berber I, Dal MS, Basturk A, Namdaroglu S, et al Convalescent plasma therapy in patients with COVID-19. J Clin Apher 2020;35 (4):367-73.

[29] Li L, Zhang W, Hu Y, Tong X, Zheng S, Yang J, et al. Effect of Convalescent Plasma Therapy on Time to Clinical Improvement in Patients With Severe and Lifethreatening COVID-19: A Randomized Clinical Trial. JAMA 2020:324(5):460-70.

[30] Graham SP, McLean RK, Spencer AJ, Belij-Rammerstorfer S, Wright D, Ulaszewska M, Edwards JC, Hayes JWP, Martini V, Thakur N, Conceicao C, Dietrich I, Shelton H, Waters R, Ludi A, Wilsden G, Browning C, Bialy D, Bhat S, StevensonLeggett P, Hollinghurst P, Gilbride C, Pulido D, Moffat K, Sharpe H, Allen E, Mioulet V, Chiu C, Newman J, Asfor AS, Burman A, Crossley S, Huo J, Owens RJ, Carrol M, Hammond JA, Tchilian E, Bailey D, Charleston B, Gilbert SC, Tuthill TJ, Lambe T. Evaluation of the immunogenicity of prime-boost vaccination with the replication-deficient viral vectored COVID-19 vaccine candidate ChAdOx1 nCoV-19. NPJ vaccines 2020;5:69.

[31] Folegatti PM, Ewer KJ, Aley PK, Angus B, Becker S, Belij-Rammerstorfer S, et al. Safety and immunogenicity of the ChAdOx $1 \mathrm{nCoV}-19$ vaccine against SARS-CoV2: a preliminary report of a phase $1 / 2$, single-blind, randomised controlled trial. Lancet 2020;396(10249):467-78.

[32] Golchin A, Seyedjafari E, Ardeshirylajimi A. Mesenchymal Stem Cell Therapy for COVID-19: Present or Future. Stem cell reviews and reports 2020;16(3):427-33.

[33] Wu F, Zhao S, Yu B, Chen YM, Wang W, Song ZG, Hu Y, Tao ZW, Tian JH, Pei YY Yuan ML, Zhang YL, Dai FH, Liu Y, Wang OM, Zheng JJ, Xu L, Holmes EC, Zhan 
YZ. A new coronavirus associated with human respiratory disease in China. Nature 2020;579(7798):265-9.

[34] Cucinotta D, Vanelli M. WHO Declares COVID-19 a Pandemic. Acta bio-medica: Atenei Parmensis 2020;91(1):157-60.

[35] Bourgonje AR, Abdulle AE, Timens W, Hillebrands JL, Navis GJ, Gordijn SJ, et al. Angiotensin-converting enzyme 2 (ACE2), SARS-CoV-2 and the pathophysiology of coronavirus disease 2019 (COVID-19). The Journal of pathology 2020;251 (3):228-48

[36] Magrone T, Magrone M, Jirillo E. Focus on Receptors for Coronaviruses with Special Reference to Angiotensin-converting Enzyme 2 as a Potential Drug TargetA Perspective. Endocrine, metabolic \& immune disorders drug targets 2020;20 (6):807-11.

[37] Li MY, Li L, Zhang Y, Wang XS. Expression of the SARS-CoV-2 cell receptor gene ACE2 in a wide variety of human tissues. Infectious diseases of poverty 2020;9 (1):45

[38] Hoffmann M, Kleine-Weber H, Schroeder S, Kruger N, Herrler T, Erichsen S, Schiergens TS, Herrler G, Wu NH, Nitsche A, Muller MA, Drosten C, Pohlmann S. SARS-CoV-2 Cell Entry Depends on ACE2 and TMPRSS2 and Is Blocked by a Clinically Proven Protease Inhibitor. Cell 2020;181(2). 271-280 e8.

[39] Ye Q, Wang B, Mao J. The pathogenesis and treatment of the 'Cytokine Storm' in COVID-19. The Journal of infection 2020;80(6):607-13.

[40] Mitra P, Misra S, Sharma P. COVID-19 Pandemic in India: What Lies Ahead. Indian journal of clinical biochemistry: IJCB 2020;35(3):380-1.

[41] Li X, Geng M, Peng Y, Meng L, Lu S. Molecular immune pathogenesis and diagnosis of COVID-19. Journal of pharmaceutical analysis 2020;10(2):102-8.

[42] Coperchini F, Chiovato L, Croce L, Magri F, Rotondi M. The cytokine storm in COVID-19: An overview of the involvement of the chemokine/chemokinereceptor system. Cytokine \& growth factor reviews 2020;53:25-32.

[43] Singhal T. A Review of Coronavirus Disease-2019 (COVID-19). Indian journal of pediatrics 2020;87(4):281-6.

[44] Atluri S, Manchikanti L, Hirsch JA. Expanded Umbilical Cord Mesenchymal Stem Cells (UC-MSCs) as a Therapeutic Strategy in Managing Critically Ill COVID-19 Patients: The Case for Compassionate Use. Pain physician 2020;23(2):E71-83.

[45] Baden LR, Rubin EJ. Covid-19-The Search for Effective Therapy. The New England journal of medicine 2020;382(19):1851-2.

[46] Ullah I, Subbarao RB, Rho GJ. Human mesenchymal stem cells-current trends and future prospective. Bioscience reports 2015;35(2):e00191.

[47] Hass R, Kasper C, Bohm S, Jacobs R. Different populations and sources of human mesenchymal stem cells (MSC): A comparison of adult and neonatal tissuederived MSC. Cell communication and signaling: CCS 2011;9:12.

[48] Baghaei K, Hashemi SM, Tokhanbigli S, Asadi Rad A, Assadzadeh-Aghdaei H, Sharifian A, Zali MR. Isolation, differentiation, and characterization of mesenchymal stem cells from human bone marrow. Gastroenterology and hepatology from bed to bench 2017;10(3):208-13.

[49] Dominici M, Le Blanc K, Mueller I, Slaper-Cortenbach I, Marini F, Krause D, Deans R, Keating A, Prockop D, Horwitz E. Minimal criteria for defining multipotent mesenchymal stromal cells. The International Society for Cellular Therapy position statement. Cytotherapy 2006;8(4):315-7.

[50] Newman RE, Yoo D, LeRoux MA, Danilkovitch-Miagkova A. Treatment of inflammatory diseases with mesenchymal stem cells. Inflammation \& allergy drug targets 2009;8(2):110-23.

[51] Alcayaga-Miranda F, Cuenca J, Khoury M. Antimicrobial Activity of Mesenchyma Stem Cells: Current Status and New Perspectives of Antimicrobial Peptide-Based Therapies. Frontiers in immunology 2017;8:339.

[52] Huang C, Wang Y, Li X, Ren L, Zhao J, Hu Y, Zhang L, Fan G, Xu J, Gu X, Cheng Z, Yu T, Xia J, Wei Y, Wu W, Xie X, Yin W, Li H, Liu M, Xiao Y, Gao H, Guo L, Xie J, Wang G, Jiang R, Gao Z, Jin Q, Wang J, Cao B. Clinical features of patients infected with 2019 novel coronavirus in Wuhan, China. Lancet 2020;395(10223):497-506.

[53] Gentile P, Sterodimas A. Adipose-derived stromal stem cells (ASCs) as a new regenerative immediate therapy combating coronavirus (COVID-19)-induced pneumonia. Expert opinion on biological therapy 2020;20(7):711-6.

[54] Gentile P, Sterodimas A, Pizzicannella J, Dionisi L, De Fazio D, Calabrese C, Garcovich S. Systematic Review: Allogenic Use of Stromal Vascular Fraction (SVF) and Decellularized Extracellular Matrices (ECM) as Advanced Therapy Medicinal Products (ATMP) in Tissue Regeneration. Int J Mol Sci 2020;21(14):4982.

[55] Gentile P, Sterodimas A, Pizzicannella J, Calabrese C, Garcovich S. Research progress on Mesenchymal Stem Cells (MSCs), Adipose-Derived Mesenchymal Stem Cells (AD-MSCs), Drugs, and Vaccines in Inhibiting COVID-19 Disease. Aging and disease 2020:11(5):1191-201.

[56] Copcu HE. Potential Using of Fat-derived Stromal Cells in the Treatment of Active Disease, and also, in Both Pre- and Post-Periods in COVID-19. Aging and disease 2020;11(4):730-6.

[57] Gentile P, Sterodimas A. Adipose Stem Cells (ASCs) and Stromal Vascular Fraction (SVF) as a Potential Therapy in Combating (COVID-19)-Disease. Aging and disease 2020;11(3):465-9.

[58] Shete A, Dhayarkar S, Sangale S, Medhe U, Panchal N, Rahane G, Yelgate R, Dhamanage A, Gangakhedkar R. Incomplete functional T-cell reconstitution in immunological non-responders at one year after initiation of antiretroviral therapy possibly predisposes them to infectious diseases. Int J Infect Dis 2019;81:114-22.

[59] Zhang Z, Fu J, Xu X, Wang S, Xu R, Zhao M, Nie W, Wang X, Zhang J, Li T, Su L, Wang FS. Safety and immunological responses to human mesenchymal stem cell therapy in difficult-to-treat HIV-1-infected patients. AIDS 2013;27(8):128393.

[60] Chandra PK, Gerlach SL, Wu C, Khurana N, Swientoniewski LT, Abdel-Mageed AB, Li J, Braun SE, Mondal D. Mesenchymal stem cells are attracted to latent
HIV-1-infected cells and enable virus reactivation via a non-canonical PI3KNFkappaB signaling pathway. Scientific reports 2018;8(1):14702.

[61] Cotter EJ, Chew N, Powderly WG, Doran PP. HIV type 1 alters mesenchymal stem cell differentiation potential and cell phenotype ex vivo. AIDS Res Hum Retroviruses 2011;27(2):187-99.

62] Huang K, Ji F, Xie Z, Wu D, Xu X, Gao H, Ouyang X, Xiao L, Zhou M, Zhu D, Li L Artificial liver support system therapy in acute-on-chronic hepatitis B liver failure: classification and regression tree analysis. Scientific reports 2019;9 (1):16462.

[63] Xie C, Zheng YB, Zhu HP, Peng L, Gao ZL. Human bone marrow mesenchymal stem cells are resistant to HBV infection during differentiation into hepatocytes in vivo and in vitro. Cell Biol Int 2009;33(4):493-500.

64] Ma R, Xing Q, Shao L, Wang D, Hao Q, Li X, Sai L, Ma L. Hepatitis B virus infection and replication in human bone marrow mesenchymal stem cells. Virol J 2011;8:486

[65] Peng L, Xie DY, Lin BL, Liu J, Zhu HP, Xie C, Zheng YB, Gao ZL. Autologous bone marrow mesenchymal stem cell transplantation in liver failure patients caused by hepatitis B: short-term and long-term outcomes. Hepatology 2011;54 (3):820-8.

66] Zhong YS, Lin N, Deng MH, Zhang FC, Tang ZF, Xu RY, Deficient proliferation of bone marrow-derived mesenchymal stem cells in patients with chronic hepatitis B viral infections and cirrhosis of the liver. Dig Dis Sci 2010;55(2):438-45.

[67] Wang Y, Wang F, Zhao H, Zhang X, Chen H, Zhang K. Human adipose-derived mesenchymal stem cells are resistant to HBV infection during differentiation into hepatocytes in vitro. Int J Mol Sci 2014;15(4):6096-110

[68] Liang B, Chen J, Li T, Wu H, Yang W, Li Y, et al. Clinical remission of a critically ill COVID-19 patient treated by human umbilical cord mesenchymal stem cells. Medicine (Baltimore) 2020:99(31):e21429.

[69] Leng Z, Zhu R, Hou W, Feng Y, Yang Y, Han Q, Shan G, Meng F, Du D, Wang S, Fan J, Wang W, Deng L, Shi H, Li H, Hu Z, Zhang F, Gao J, Liu H, Li X, Zhao Y, Yin K, He X, Gao Z, Wang Y, Yang B, Jin R, Stambler I, Lim LW, Su H, Moskalev A, Cano A Chakrabarti S, Min KJ, Ellison-Hughes G, Caruso C, Jin K, Zhao RC. Transplantation of ACE2(-) Mesenchymal Stem Cells Improves the Outcome of Patients with COVID-19 Pneumonia. Aging and disease 2020;11(2):216-28.

[70] B.B.C. Research, FDA approved mesenchymal stem cell (MSC) treatments as compassionate use in the very sickest COVID-19 patients., 2020. https:// bbcrconsulting.com/clinical-trials/fda-approved-mesenchymal-stem-cell-msctreatments-as-compassionate-use-in-the-very-sickest-covid-19-patients/. (Accessed 21 May 2020).

[71] V. Rees, US researchers to study stem cell therapy in COVID-19 patients, 2020. https://www.europeanpharmaceuticalreview.com/news/116794/us-researchers-to-study-stem-cell-therapy-in-covid-19-patients/. (Accessed 21 May 2020).

[72] D. Patel, GIOSTAR Announces FDA Approval Under Compassionate Use for a COVID-19 Clinical Trial with Stem Cells, 2020. https://www.prnewswire.com/ news-releases/giostar-announces-fda-approval-under-compassionate-use-fora-covid-19-clinical-trial-with-stem-cells-301051830.html (Accessed 21 May 2020).

[73] B. Disptach, First patients dosed in Mesoblast COVID-19 trial, 2020. https://biotechdispatch.com.au/news/first-patients-dosed-in-mesoblast-covid-19-trial. (Accessed 23 May 2020).

[74] J. Meldrum, Bothwell, K., First Patients Dosed in Phase 2/3 Randomized Controlled Trial of Mesoblast's Remestemcel-l for COVID-19 Acute Respiratory Distress Syndrome, 2020. https://www.globenewswire.com/news-release/2020/ 05/06/2028234/0/en/First-Patients-Dosed-in-Phase-2-3-Randomized-Controlled-Trial-of-Mesoblast-s-Remestemcel-l-for-COVID-19-Acute-RespiratoryDistress-Syndrome.html. (Accessed 23 May 2020).

[75] L. Parsons, Mesoblast expands compassionate use COVID-19 programme, 2020. https://www.pmlive.com/pharma_news/mesoblast_expands_compassionate_use_covid-19 programme 1344461\#: *text=Will\%20now\%20include \%20children\%20with \%20multisystem\%20inflammatory\%20syndrome\&text=Australian\%2 Dbased \%20regenerative\%20medicine\%20company,children\%20infected \%20with\%20 COVID\%2D19. (Accessed 27 July 2020).

[76] D. Rubin, U.S. FDA Clears Pluristem's IND Application for Phase II COVID-19 Study, 2020. https://www.globenewswire.com/news-release/2020/05/08/ 2030212/0/en/U-S-FDA-Clears-Pluristem-S-IND-Application-for-Phase-IICOVID-19-Study.html. (Accessed 25 May 2020).

[77] R. Staff, Novel Stem Cell Therapy for COVID-19-related ARDS in Development, 2020. https://www.rtmagazine.com/products-treatment/pharmaceuticals/uspharmaceuticals/stem-cells-covid-19-ards. (Accessed 26 May 2020).

[78] R. Weermeijer, Athersys and UH Cleveland trial stem cell therapy for Covid-19, 2020. https://www.clinicaltrialsarena.com/news/athersys-stem-cell-therapycovid-19/. (Accessed 25 May 2020).

[79] A. Staff, COVID-19 and other Viral Induced ARDS, 2020. https://www.athersys. com/clinical-trials/ards/default.aspx. (Accessed 27 July 2020 2020).

[80] R. Macdonald, LaCagnina, C., Cynata Receives Ethics Approval to Commence Clinical Trial in COVID-19 and Clinical Development Update, 2020. https://www. globenewswire.com/news-release/2020/05/08/2030332/0/en/Cynata-ReceivesEthics-Approval-to-Commence-Clinical-Trial-in-COVID-19-and-Clinical-Development-Update.html. (Accessed 27 May 2020).

[81] Sanchez-Guijo F, Garcia-Arranz M, Lopez-Parra M, Monedero P, Mata-Martinez C, Santos A, Sagredo V, Alvarez-Avello JM, Guerrero JE, Perez-Calvo C, SanchezHernandez MV, Del-Pozo JL, Andreu EJ, Fernandez-Santos ME, Soria-Juan B, Hernandez-Blasco LM, Andreu E, Sempere JM, Zapata AG, Moraleda JM, Soria B, Fernandez-Aviles F, Garcia-Olmo D, Prosper F. Adipose-derived mesenchymal stromal cells for the treatment of patients with severe SARS-CoV-2 pneumonia 
requiring mechanical ventilation. A proof of concept study. EClinicalMedicine 2020;25:100454

[82] Matthay MA, Calfee CS, Zhuo H, Thompson BT, Wilson JG, Levitt JE, Rogers AJ, Gotts JE, Wiener-Kronish JP, Bajwa EK, Donahoe MP, McVerry BJ, Ortiz LA, Exline M, Christman JW, Abbott J, Delucchi KL, Caballero L, McMillan M, McKenna DH, Liu KD. Treatment with allogeneic mesenchymal stromal cells for moderate to severe acute respiratory distress syndrome (START study): a randomised phase 2a safety trial. The Lancet. Respiratory medicine 2019;7(2):154-62.

[83] Bari E, Ferrarotti I, Saracino L, Perteghella S, Torre ML, Corsico AG. Mesenchymal Stromal Cell Secretome for Severe COVID-19 Infections: Premises for the Therapeutic Use. Cells 2020;9(4):924.

[84] Sanap A, Bhonde R, Kharat A, Kheur S. Mesenchymal Stem Cells Secretome as a prospective therapeutic option for COVID-19 patients, Drug Target Review, Russell Publishing Ltd, Kent, United Kingdom 2020; 13 April:1-3

[85] Ponte AL, Marais E, Gallay N, Langonne A, Delorme B, Herault O, Charbord P, Domenech J. The in vitro migration capacity of human bone marrow mesenchymal stem cells: comparison of chemokine and growth factor chemotactic activities. Stem cells 2007;25(7):1737-45.

[86] Ruster B, Gottig S, Ludwig RJ, Bistrian R, Muller S, Seifried E, Gille J, Henschler R. Mesenchymal stem cells display coordinated rolling and adhesion behavior on endothelial cells. Blood 2006;108(12):3938-44.

[87] Segers VF, Van Riet I, Andries LJ, Lemmens K, Demolder MJ, De Becker AJ, Kockx MM, De Keulenaer GW. Mesenchymal stem cell adhesion to cardiac microvascular endothelium: activators and mechanisms. American journal of physiology. Heart and circulatory physiology 2006;290(4):H1370-7.

[88] Shi Y, Su J, Roberts AI, Shou P, Rabson AB, Ren G. How mesenchymal stem cells interact with tissue immune responses. Trends in immunology 2012:33(3):136-43.

[89] Meirelles Lda S, Fontes AM, Covas DT, Caplan AI. Mechanisms involved in the therapeutic properties of mesenchymal stem cells. Cytokine \& growth factor reviews 2009;20(5-6):419-27.

[90] Mao F, Kang JJ, Cai X, Ding NF, Wu YB, Yan YM, Qian H, Zhang X, Xu WR. Crosstalk between mesenchymal stem cells and macrophages in inflammatory bowel disease and associated colorectal cancer. Contemporary oncology 2017;21(2):91-7.

[91] Zhang R, Liu Y, Yan K, Chen L, Chen XR, Li P, Chen FF, Jiang XD. Anti-inflammatory and immunomodulatory mechanisms of mesenchymal stem cell transplantation in experimental traumatic brain injury. Journal of neuroinflammation 2013;10:106.

[92] Le Blanc K, Rasmusson I, Sundberg B, Gotherstrom C, Hassan M, Uzunel M, Ringden $\mathrm{O}$. Treatment of severe acute graft-versus-host disease with third party haploidentical mesenchymal stem cells. Lancet 2004;363(9419):1439-41.

[93] Stemberger S, Jamnig A, Stefanova N, Lepperdinger G, Reindl M, Wenning GK. Mesenchymal stem cells in a transgenic mouse model of multiple system atrophy: immunomodulation and neuroprotection. PloS one 2011;6(5):e19808.

[94] Lucas R, Verin AD, Black SM, Catravas JD. Regulators of endothelial and epithelial barrier integrity and function in acute lung injury. Biochem Pharmacol 2009;77 (12):1763-72.

[95] Zhu H, Xiong Y, Xia Y, Zhang R, Tian D, Wang T, Dai J, Wang L, Yao H, Jiang H, Yang K, Liu E, Shi Y, Fu Z, Gao L, Zou L. Therapeutic Effects of Human Umbilical Cord-Derived Mesenchymal Stem Cells in Acute Lung Injury Mice. Scientific reports 2017;7:39889.

[96] Iyer SS, Rojas M. Anti-inflammatory effects of mesenchymal stem cells: novel concept for future therapies. Expert opinion on biological therapy 2008;8 (5):569-81.

[97] Pedrazza L, Cunha AA, Luft C, Nunes NK, Schimitz F, Gassen RB, Breda RV, Donadio MV, de Souza Wyse AT, Pitrez PMC, Rosa JL, de Oliveira JR. Mesenchymal stem cells improves survival in LPS-induced acute lung injury acting through inhibition of NETs formation. Journal of cellular physiology 2017;232(12):3552-64.

[98] Hall SR, Tsoyi K, Ith B, Padera Jr. RF, Lederer JA, Wang Z, Liu X, Perrella MA. Mesenchymal stromal cells improve survival during sepsis in the absence of heme oxygenase-1: the importance of neutrophils. Stem cells 2013;31(2):397-407.

[99] Mei SH, Haitsma JJ, Dos Santos CC, Deng Y, Lai PF, Slutsky AS, Liles WC, Stewart DJ. Mesenchymal stem cells reduce inflammation while enhancing bacterial clearance and improving survival in sepsis. American journal of respiratory and critical care medicine 2010;182(8):1047-57.

[100] Ye LZ, Zhang AD, Shi HP, Zhao SM, Luo HY, Yuan LF, Ma SW, Li SH, Cheng ZY, Zhao Y, et al. Analysis of 4628 cases in the genetic counselling clinic of PUMC Hospital, Proceedings of the Chinese Academy of Medical Sciences and the Peking Union Medical College = Chung-kuo i hsueh k'o hsueh yuan. Chung-kuo hsieh ho i k'o ta hsueh hsueh pao 1989:4(3):126-30.

[101] Belkaid Y, Tarbell K. Regulatory T cells in the control of host-microorganism interactions $\left({ }^{*}\right)$. Annual review of immunology 2009;27:551-89.

[102] dos Santos CC, Murthy S, Hu P, Shan Y, Haitsma JJ, Mei SH, Stewart DJ, Liles WC. Network analysis of transcriptional responses induced by mesenchymal stem cell treatment of experimental sepsis. The American journal of pathology 2012;181(5):1681-92.

[103] Islam MN, Das SR, Emin MT, Wei M, Sun L, Westphalen K, Rowlands DJ, Quadri SK, Bhattacharya S, Bhattacharya J. Mitochondrial transfer from bone-marrow- derived stromal cells to pulmonary alveoli protects against acute lung injury Nature medicine 2012;18(5):759-65.

[104] Jackson MV, Morrison TJ, Doherty DF, McAuley DF, Matthay MA, Kissenpfennig A, O'Kane CM, Krasnodembskaya AD. Mitochondrial Transfer via Tunneling Nanotubes is an Important Mechanism by Which Mesenchymal Stem Cells Enhance Macrophage Phagocytosis in the In Vitro and In Vivo Models of ARDS Stem cells 2016;34(8):2210-23.

[105] Guery BP, Mason CM, Dobard EP, Beaucaire G, Summer WR, Nelson S. Keratinocyte growth factor increases transalveolar sodium reabsorption in normal and injured rat lungs. American journal of respiratory and critical care medicine $1997 ; 155(5): 1777-84$

[106] Shyamsundar M, McAuley DF, Ingram RJ, Gibson DS, O'Kane D, McKeown ST Edwards A, Taggart C, Elborn JS, Calfee CS, Matthay MA, O'Kane CM. Keratinocyte growth factor promotes epithelial survival and resolution in a human model of lung injury. American journal of respiratory and critical care medicine 2014;189 (12):1520-9.

[107] Wang S, Mo M, Wang J, Sadia S, Shi B, Fu X, Yu L, Tredget EE, Wu Y. Plateletderived growth factor receptor beta identifies mesenchymal stem cells with enhanced engraftment to tissue injury and pro-angiogenic property. Cellular and molecular life sciences: CMLS 2018;75(3):547-61.

[108] Mei SH, McCarter SD, Deng Y, Parker CH, Liles WC, Stewart DJ. Prevention of LPSinduced acute lung injury in mice by mesenchymal stem cells overexpressing angiopoietin 1. PLoS medicine 2007;4(9):e269.

[109] He H, Liu L, Chen Q, Liu A, Cai S, Yang Y, Lu X, Qiu H. Mesenchymal Stem Cells Overexpressing Angiotensin-Converting Enzyme 2 Rescue LipopolysaccharideInduced Lung Injury. Cell transplantation 2015;24(9):1699-715.

[110] Yang JX, Zhang N, Wang HW, Gao P, Yang OP, Wen OP. CXCR4 receptor overexpression in mesenchymal stem cells facilitates treatment of acute lung injury in rats. The Journal of biological chemistry 2015;290(4):1994-2006

[111] Wang H, Yang YF, Zhao L, Xiao FJ, Zhang QW, Wen ML, Wu CT, Peng RY, Wang LS. Hepatocyte growth factor gene-modified mesenchymal stem cells reduce radiation-induced lung injury. Human gene therapy 2013;24(3):343-53.

[112] Loy H, Kuok DIT, Hui KPY, Choi MHL, Yuen W, Nicholls JM, Peiris JSM, Chan MCW. Therapeutic Implications of Human Umbilical Cord Mesenchymal Stroma Cells in Attenuating Influenza A(H5N1) Virus-Associated Acute Lung Injury. The Journal of infectious diseases 2019;219(2):186-96.

[113] Wu X, Dao Thi VL, Huang Y, Billerbeck E, Saha D, Hoffmann HH, Wang Y, Silva LAV, Sarbanes S, Sun T, Andrus L, Yu Y, Ouirk C, Li M, MacDonald MR, Schneider WM, An X, Rosenberg BR, Rice CM. Intrinsic Immunity Shapes Viral Resistance of Stem Cells. Cell 2018;172(3). 423-438 e25.

[114] Huang IC, Bailey CC, Weyer JL, Radoshitzky SR, Becker MM, Chiang JJ, Brass AL, Ahmed AA, Chi X, Dong L, Longobardi LE, Boltz D, Kuhn JH, Elledge SJ, Bavari S, Denison MR, Choe H, Farzan M. Distinct patterns of IFITM-mediated restriction of filoviruses, SARS coronavirus, and influenza A virus. PLoS pathogens 2011;7 (1):e1001258.

[115] Bailey CC, Zhong G, Huang IC, Farzan M. IFITM-Family Proteins: The Cell's First Line of Antiviral Defense. Annual review of virology 2014;1:261-83.

[116] Ziegler CGK, Allon SJ, Nyquist SK, Mbano IM, Miao VN, Tzouanas CN, Cao Y, Yousif AS, Bals J, Hauser BM, Feldman J, Muus C, Wadsworth 2nd MH, Kazer SW, Hughes TK, Doran B, Gatter GJ, Vukovic M, Taliaferro F, Mead BE, Guo Z, Wang JP, Gras D, Plaisant M, Ansari M, Angelidis I, Adler H, Sucre JMS, Taylor CJ, Lin B, Waghray A, Mitsialis V, Dwyer DF, Buchheit KM, Boyce JA, Barrett NA, Laidlaw TM, Carroll SL, Colonna L, Tkachev V, Peterson CW, Yu A, Zheng HB, Gideon HP, Winchell CG, Lin PL, Bingle CD, Snapper SB, Kropski JA, Theis FJ, Schiller HB, Zaragosi LE, Barbry P, Leslie A, Kiem HP, Flynn JL, Fortune SM, Berger B, Finberg RW, Kean LS, Garber M, Schmidt AG, Lingwood D, Shalek AK, Ordovas-Montanes J SARS-CoV-2 Receptor ACE2 Is an Interferon-Stimulated Gene in Human Airway Epithelial Cells and Is Detected in Specific Cell Subsets across Tissues. Cell 2020;181(5). 1016-1035 e19.

[117] Li X, Molina-Molina M, Abdul-Hafez A, Uhal V, Xaubet A, Uhal BD. Angiotensin converting enzyme- 2 is protective but downregulated in human and experimental lung fibrosis. American journal of physiology. Lung cellular and molecular physiology 2008;295(1):L178-85.

[118] He HL, Liu L, Chen QH, Cai SX, Han JB, Hu SL, Chun P, Yang Y, Guo FM, Huang YZ, Oiu HB. MSCs modified with ACE2 restore endothelial function following LPS challenge by inhibiting the activation of RAS. Journal of cellular physiology 2015;230(3):691-701.

[119] Niu MJ, Yang JK, Lin SS, Ji XJ, Guo LM. Loss of angiotensin-converting enzyme 2 leads to impaired glucose homeostasis in mice. Endocrine 2008:34(1-3):56-61.

[120] Roberts MA, Velkoska E, Ierino FL, Burrell LM. Angiotensin-converting enzyme 2 activity in patients with chronic kidney disease. Nephrology, dialysis, transplantation: official publication of the European Dialysis and Transplant Association European Renal Association 2013;28(9):2287-94.

[121] Zhong JC, Huang DY, Yang YM, Li YF, Liu GF, Song XH, Du K. Upregulation of angiotensin-converting enzyme 2 by all-trans retinoic acid in spontaneously hypertensive rats. Hypertension 2004:44(6):907-12. 